\title{
Hydrogel-coated feed spacers in two-phase flow cleaning in spiral wound membrane elements: A novel platform for eco-friendly biofouling mitigation
}

Yusuf Wibisono, Wetra Yandi, Mohsen Golabi, Roni Nugraha, Emile R. Cornelissen, Antoine J. B. Kemperman, Thomas Ederth and Kitty Nijmeijer

\section{Linköping University Post Print}

\section{Tweet}

N.B.: When citing this work, cite the original article.

Original Publication:

Yusuf Wibisono, Wetra Yandi, Mohsen Golabi, Roni Nugraha, Emile R. Cornelissen, Antoine J. B. Kemperman, Thomas Ederth and Kitty Nijmeijer, Hydrogel-coated feed spacers in twophase flow cleaning in spiral wound membrane elements: A novel platform for eco-friendly biofouling mitigation, 2015, Water Research, (71), 171-186.

http://dx.doi.org/10.1016/j.watres.2014.12.030

Copyright: IWA Publishing

http://www.iwaponline.com/

Postprint available at: Linköping University Electronic Press $\underline{\text { http://urn.kb.se/resolve?urn=urn:nbn:se:liu:diva-117658 }}$ 


\title{
Hydrogel-coated feed spacers in two-phase flow cleaning in spiral wound membrane elements: a novel platform for eco-friendly biofouling mitigation
}

\author{
Yusuf Wibisono ${ }^{1,4 \#}$, Wetra Yandi ${ }^{2 \#, ~ M o h s e n ~ G o l a b i ~}{ }^{3}$, Roni Nugraha², Emile R. \\ Cornelissen $^{5}$, Antoine J.B. Kemperman ${ }^{*}$, Thomas Ederth², Kitty Nijmeijer ${ }^{1}$
}

1 University of Twente, Membrane Science and Technology, MESA+ Institute of Nanotechnology, Faculty of Science and Technology, P.O. Box 217, 7500 AE, Enschede, The Netherlands

${ }^{2}$ Linköping University, Division of Molecular Physics, Department of Physics, Chemistry and Biology (IFM), SE-581 83 Linköping, Sweden

${ }^{3}$ Linköping University, Division of Biosensors and Bioelectronics, Department of Physics, Chemistry and Biology (IFM), SE-581 83 Linköping, Sweden

${ }^{4}$ Wetsus, Centre of Excellence for Sustainable Water Technology, P.O. Box 1113, 8900 CC, Leeuwarden, The Netherlands

${ }^{5}$ KWR Watercycle Research Institute, P.O. Box 1072, 3430 BB, Nieuwegein, The Netherlands

\#Both authors contributed equally to this work.

*Corresponding author. Tel.: +31-53-4892956; Fax.: +31-53-4894611

Email address: a.j.b.kemperman@utwente.nl (A.J.B. Kemperman)

\section{Keywords:}

Hydrogel, charge, biofouling, two-phase flow, feed spacer, spiral-wound membrane 


\begin{abstract}
Biofouling is still a major challenge in the application of nanofiltration and reverse osmosis membranes. Here we present a platform approach for environmentally friendly biofouling control using a combination of a hydrogel-coated feed spacer and two-phase flow cleaning. Neutral (polyHEMA-co-PEG ${ }_{10} \mathrm{MA}$ ), cationic (polyDMAEMA) and anionic (polySPMA) hydrogels have been successfully grafted onto polypropylene (PP) feed spacers via plasmamediated UV-polymerization. These coatings maintained their chemical stability after 7 days incubation in neutral ( $\mathrm{pH}$ 7), acidic ( $\mathrm{pH}$ 5) and basic ( $\mathrm{pH}$ 9) environments. Anti-biofouling properties of these coatings were evaluated by E. coli attachment assay and nanofiltration experiments at a TMP of $600 \mathrm{kPag}$ using tap water with additional nutrients as feed and by using optical coherence tomography. Especially the anionic polySPMA-coated PP feed spacer shows reduced attachment of $E$. coli and biofouling in the spacer-filled narrow channels resulting in delayed biofilm growth. Employing this highly hydrophilic coating during removal of biofouling by two-phase flow cleaning also showed enhanced cleaning efficiency, feed channel pressure drop and flux recoveries. The strong hydrophilic nature and the presence of negative charge on polySPMA are most probably responsible for the improved antifouling behavior. A combination of polySPMA-coated PP feed spacers and two-phase flow cleaning therefore is promising and an environmentally friendly approach to control biofouling in NF/RO systems employing spiral-wound membrane modules.
\end{abstract}




\section{Introduction}

High pressure membrane processes, i.e. nanofiltration (NF) and reverse osmosis (RO) are the most commonly applied membrane processes for the removal of contaminants and pathogens from drinking water supplies (Greenlee et al. 2009, Hilal et al. 2004). However, despite their widespread application worldwide, biofouling remains a major obstacle since it lowers the performance of NF/RO plants (Matin et al. 2011).

Commonly practiced biofouling control by using chemical agents (alkalines, detergents, enzymes, chelating agents, acids, biocides) were found ineffective in removing biofouling completely from NF/RO spiral wound membrane channels (Creber et al. 2010, Hijnen et al. 2012). Besides promoting membrane damages and being harmful to the environment, the use of biocides may promote the resistance of microorganisms towards these biocides and worsen the biofouling problems (Applegate et al. 1989). Re-growth of biofouling was observed after chemical cleaning, due to the presence of dead bacteria, which served as nutrients for subsequent growth. Physical removal of remaining biomass is therefore essential to optimize biofouling control (Bereschenko et al. 2011). The presence of spacers in the membrane modules has a significant contribution to the occurrence of biofouling and especially the feed spacer is a source for biomass growth inducing befouling. Biofouling removal from membrane feed channels using two-phase flow was found effective and can be used as an environment and membrane friendly cleaning method (Wibisono et al. 2014, Wibisono et al. 2015).

In our previous work, we investigated the role of feed spacer geometry, feed pressure, gas/liquid ratio, cleaning duration, and liquid velocity on biofouling removal in spiral wound membrane elements (Wibisono et al. 2015). However, in order to reduce the occurrence of biofouling, prevention at the source is the preferred option. In this work we therefore investigate the influence of charge of the employed spacers using hydrogel coated polypropylene (PP) feed spacers, and its effect on prevention of early attachment of biofouling. Although the effect of 
charge on the anti-biofouling properties has been investigated before, the effect of charge of a polymer coated feed spacer filament has however, not been investigated systematically so far. Three hydrogels with different charge (neutral: polyHEMA-co-PEG $10 \mathrm{MA}$; cationic: polyDMAEMA and anionic: polySPMA) were selected and coated onto a polypropylene (PP) feed spacer. It is indeed interesting to also include the zwitterionic or pseudo-zwitterionic coatings in this work since these materials have been widely studied and showed their prominent antifouling properties. However, in this study we are interested to see the performance of charge coatings on the spacers in the early attachment of biofouling and how that coatings influence the membrane filtration in general. We expect that charge interaction between coatings material in the spacers with fouling microorganisms, which mostly have charge potential and charged-macromolecules secreted by the organisms (e.g. polysaccharides, proteins etc.) in the early attachment of biofouling will affect the performance of membrane filtration NF/RO system. This allowed us to systematically investigate the anti-biofouling effect of the feed spacer charge using bacteria attachment tests and biofouling evaluation in nanofiltration experiments. We aim at providing a novel eco-friendly method to control biofouling in NF/RO systems by a combination of charged hydrogel-coated PP feed spacers and two-phase flow cleaning.

\section{Theory of feed spacer coating}

Biofilms initially grow alongside the feed spacer, and eventually attach to the membrane surface (Baker et al. 1995). The feed spacer is responsible for the accumulation of biomass in the membrane channels. Although numerous studies on membrane surface modification (Vrouwenvelder et al. 2009) exist, the literature on spacer surface modification is less abundant. Surface modifications of feed spacers have been studied using metal coatings, e.g. silver and copper (Araújo et al. 2012a, Hausman et al. 2010) or functionalized polymers, 
e.g. polydopamine, polydopamine-g-poly(ethylene glycol) and diglyme plasma coating (Araújo et al. 2012b, Reid et al. 2014).

The aforementioned surface coatings showed some limitations. Toxic coatings (silver, copper, biocide etc.) act similarly to chemical cleaning, the first layer of bacterial cells might be killed, but the material from dead bacteria provides nutrients for subsequent bacterial growth (Araújo et al. 2012a). For polydopamine and polydopamine-g-poly(ethylene glycol) coatings, although batch adhesion tests using bacterial solutions or proteins under static conditions showed good anti-biofouling properties, long-term and continuous biofouling experiments demonstrated poor biofouling inhibition (Miller et al. 2012). The results might be related to instability of those polymers during long-term experiments. The potential of more stable hydrophilic coatings to facilitate membrane cleaning is therefore still promising (Miller et al. 2012). Moreover, polydopamine is amphoteric and differently charged in acidic and basic environments (Liu et al. 2014), and the results suggest that surface charge affects the early attachment of biofouling on the feed spacer surface, since electrostatic interactions between surfaces and the charged outer layer of cell membranes of fouling organisms can play a role. Hydrogel-based materials have been reported to have good anti-biofouling properties and have great potential to be applied as antifouling coatings (Chang et al. 2010). Their antifouling properties might be correlated with the charge, entropic elasticity and strong surface hydration of the hydrogels (Murosaki et al. 2011). Poly ethylene glycol (PEG) based coating materials are well known for their remarkable antifouling properties (Ekblad et al. 2008). Cationic polyDMAEMA has also been reported as a potential antimicrobial material (Liu et al. 2007), as has the anionic counterpart polySPMA (Wan et al. 2012).

Considering that the net charge of the cell wall of most bacteria that cause biofouling is negative (Bereschenko et al. 2010), it is important to investigate the effect of spacer charge (i.e. coating charge for coated spacers) on biofouling control. In addition, some 
biofouling organisms secrete bioadhesives, which also consist of charged polysaccharides and proteins (Stanley et al. 1999).

\section{Experimental section}

\subsection{Materials}

A polypropylene (PP) feed spacer with a thickness of $0.7 \mathrm{~mm}$ was provided by Delstar Technology Inc., UK. 2-hydroxyethyl methacrylate (HEMA), polyethylene glycol methacrylate (PEG $\left.{ }_{10} \mathrm{MA}\right)$, 3-sulfopropyl methacrylate potassium salt (SPMA), 2dimethylaminoethyl methacrylate (DMAEMA), and nutrient broth bacterial culture media were purchased from Sigma-Aldrich Sweden AB. Crystal violet, a Gram-color modified kit for Gram staining was purchased from Merck, Sweden. All chemicals were used without further purification. Bacterial attachment assays were carried out using 12-well polystyrene culture plates sterilized by gamma irradiation (VWR, Sweden). Thin film composite ESNA1-LF2 NF membranes and permeate spacers were obtained from Hydranautics, Oceanside, Californa, USA. Sodium acetate $\left(\mathrm{CH}_{3} \mathrm{COONa}\right)$, sodium nitrate $\left(\mathrm{NaNO}_{3}\right)$, anhydrous monobasic sodium phosphate $\left(\mathrm{NaH}_{2} \mathrm{PO}_{4}\right)$ and sodium hydroxide $(\mathrm{NaOH})$ were purchased from Sigma-Aldrich (Germany) and used as received.

\subsection{Plasma-mediated UV-polymerization}

The grafting of charged hydrophilic polymers onto a PP feed spacer surface using plasma treatment of PP and UV-photopolymerization can be generally divided into two steps (Figure 1). The first step is the activation of the PP surface by oxygen plasma. After 15 minutes exposure to oxygen plasma at room temperature, hydroxyl, peroxide and carbonyl functional groups are produced. The second step is the grafting of the monomers onto the activated PP surfaces by UV-polymerization $(\lambda=365 \mathrm{~nm})$. 
Figure 2 illustrates the preparation of the modified feed spacer by coating with the hydrophilic polymers. Polypropylene feed spacer samples were sonicated for $15 \mathrm{~min}$ in acetone to remove residual chemicals from the manufacturing, dried and weighed. The samples

were then treated with oxygen plasma (standard plasma-system Pico, Diener, Germany) for 15 min, under approximately 10Pa oxygen partial pressure at approximately $200 \mathrm{~W}$. Samples were then immediately incubated in $0.4 \mathrm{M}$ solution of monomers (HEMA and PEG ${ }_{10} \mathrm{MA}$, SPMA, or DMAEMA) in water for 24 hours at room temperature. For photopolymerization, the incubated samples were placed immediately without further drying between two transparent quartz discs and irradiated by UV light $(\lambda=365 \mathrm{~nm})$ for 2 hours. The reaction chamber was purged with moist nitrogen gas for $1 \mathrm{~min}$ before and during UV-polymerization to prevent interference of oxygen and to prevent the solvent from evaporating.

After irradiation, the spacer was soaked in water for 24 hours to remove un-reacted monomers and other chemical residues. The samples were then dried in an incubator at $100{ }^{\circ} \mathrm{C}$ for $48 \mathrm{~h}$ and weighed. The percentage of grafting (PG) of polymer on the spacers was calculated using the following equation:

$$
P G(\%)=\frac{w_{p}-w_{0}}{w_{0}} \times 100 \%
$$

where $w_{0}$ and $w_{p}$ are the weights of the spacer before and after polymerization, respectively. Three replicates of each test sample were used in this work.

\subsection{Polymer characterization}

All pristine and hydrogel-coated polypropylene (PP) spacers were characterized using Fourier-Transform Infrared Attenuated Total Reflection (FTIR-ATR) spectroscopy using a Pike MIRacle ATR accessory with a diamond prism in a Vertex70 FT-IR Spectrometer 
(Bruker, Germany) equipped with a DTGS detector. The samples were pressed against the prism with a swivel tip, which is used for non-plated surfaces and makes it possible to hold the substrate by adjusting or twisting its position on the substrate surface. OPUS 7.2 software was used for data acquisition and processing. The spectra were recorded over the wavenumber range $4600-600 \mathrm{~cm}^{-1}$ and at a spectral resolution of $4 \mathrm{~cm}^{-1}$. IR spectra of pristine and hydrogel-coated PP were recorded after polymerization, chemical stability test and post-filtration evaluation, respectively.

Surface roughness and topography of pristine and hydrogel-coated PP were examined by a NanoScope IVa Dimension 3100 SPM Atomic Force Microscope (AFM) (Veeco Instruments, Inc., USA). The images were recorded over an area of $5 \times 5 \mathrm{~m}^{2}$ in tapping mode in air at a line scan acquisition rate of $1 \mathrm{~Hz}$.

In order to measure the wettability of the coatings, SPMA, HEMA-PEG ${ }_{10} \mathrm{MA}$, and DMAEMA were polymerized onto intiator-immobilized gold surfaces via surface mediated atom transfer radical polymerization (SI-ATRP). The thickness of these coatings was adjusted to $100 \AA$. The captive bubble technique was used to measure the contact angle of the hydrated polymer coatings using a Dataphysics OCA35 contact angle analyzer with software SCA22. After equilibrating the coating samples in water for $1 \mathrm{~h}$, the samples were placed facing downwards in a glass container filled with deionized water. $2 \mu 1$ of air was released to the polymer surfaces by a U-shaped needle under control of a computer system. Three contact angles of the bubble were measured and the values were averaged.

\subsection{Polymer stability test}

To evaluate the stability of the grafted polymers in water, acidic and basic environments, and after short- and long-term immersion, hydrogel-coated spacers were

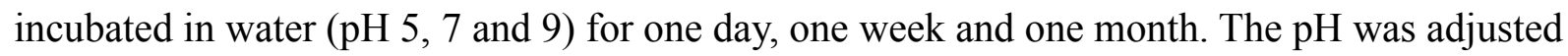


by adding hydrochloric acid $(0.1 \mathrm{M})$ and sodium hydroxide $(0.1 \mathrm{M})$ to deionized water (MilliQ). The temperature used in this study was $5^{\circ} \mathrm{C}$ to avoid the growth of microorganisms, to exclude any effect of biofouling on the stability of the coating, as the presence of microorganisms might change the $\mathrm{pH}$ of system as these secrete metabolites. The weight and IR spectra of the samples were measured before and after incubation. The samples were washed several times in Milli-Q water and dried prior to the measurements. The loss of polymer coating in terms of weight loss (WL) was calculated using:

$W L=W_{f}-W_{i}$

where $W_{f}$ and $W_{i}$ are the weight of the spacer after and before incubation, respectively.

\subsection{Bacterial attachment assay}

Escherichia coli (CCUG 3274) were cultured in nutrient broth (NB) medium at $37^{\circ} \mathrm{C}$ by shaking at $170 \mathrm{rpm}$ for 16 hours. Fresh sterile NB medium was then added to the bacterial suspension and the optical density was adjusted to 0.1 (approximately $10^{8} \mathrm{cfu} / \mathrm{ml}$ ) at $600 \mathrm{~nm}$. Four replicates of each feed spacer sample (pristine and hydrogel-coated PPs) were placed in 12-well polystyrene plates and $4 \mathrm{ml}$ of bacterial suspension was dispensed to each well. The plates were incubated at $37^{\circ} \mathrm{C}$ and $75 \mathrm{rpm}$ for 1,4 or 24 hours. After incubation, the samples were washed several times in Milli-Q water and transferred to a new well plate. $4 \mathrm{ml}$ of crystal violet $0.3 \%$ was added to each well. After 15 min incubation at room temperature, samples were gently washed three times by Milli-Q water to remove non-bound bacterial cells and extra stain. The washed samples were immersed in a new well plate containing $4 \mathrm{ml}$ of ethanol $95 \%(\mathrm{v} / \mathrm{v})$ for 20 min to release crystal violet from the bacteria cell walls. The optical density (OD) of the solution in each well was measured at $540 \mathrm{~nm}$. 
Four replicates of each sample, incubated with fresh sterile NB without bacteria, but otherwise treated similarly, were used as negative controls in this experiment. The optical density of crystal violet from bacteria was corrected by subtracting its mean OD from the negative control prior to statistical analysis. To obtain the images of bacteria on the spacer surfaces, the samples were fixed in $10 \mathrm{~mL}$ of $2.5 \%(\mathrm{v} / \mathrm{v})$ glutaraldehyde for $20 \mathrm{~min}$ at room temperature. After washing in Milli-Q water and air-drying, the samples were attached to the sample holder using double-sided carbon tape. The surface of the samples was sprayed by compressed gas to remove any lose particles and debris. Bacteria on the feed spacers were detected by a Phenom (FEI, Eindhoven, Netherlands) desktop scanning electron microscope (SEM). The SEM images are displayed as inverted images to enhance the visibility of the bacteria cells.

The relative attachment of bacteria to the hydrogel-coated samples is presented as the optical density of the bacteria at $540 \mathrm{~nm}\left(\mathrm{OD}_{540 \mathrm{~nm}}\right)$ on the spacer surface and normalized to the uncoated spacer. Error bars represent the standard deviation from 4 replicates of each sample. Statistical analysis of these data was carried out using Minitab 16 statistical software. One-way Analysis of Variance (ANOVA) with $\alpha=5 \%$ and Tukey's HSD Post-hoc test were performed to determine the difference between hydrogel-coated and uncoated samples. Values were considered significantly different from each other when $p$-value $(p)<0.05$.

\subsection{Filtration tests}

Figure 3 shows the schematic diagram of the filtration test set-up used. The lower part shows the feed water before entering the filtration cells. Tap water (Enschede, The Netherlands) used as feed. Before storage in a 60 liter feed tank, the feed water was filtered by a cartridge filter (1-3 $\mu$ m polypropylene wound FA10", Purtrex PX01-10, USA). The feed tank was equipped with a floating switch valve to regulate the water level. Storage of the feed water 
in the feed tank, resulted in a water temperature approximately equal to the room temperature. To promote accelerated biofouling growth, nutrients were added to the feed after the feed tank by using a peristaltic pump (Masterflex L/S pumps, Cole-Palmer Instrument Company, USA). The feed water was then pumped and equally distributed into three lines using a high pressure feed pump (Micropump GAF series, Micropump Inc., Canada).

In the upper part of the filtration set-up, a mass flow controller (Cori-Flow, Bronkhorst, The Netherlands: $10 \pm 0.02 \mathrm{~L} / \mathrm{h}$ max), regulated the flow rate within each line and allowed equal feed flow to each vertically positioned filtration cell. The filtration cells were covered from direct light to prevent growth of phototrophic organisms like algae. The feed channel pressure drop of the filtration cell was measured using a differential pressure sensor (EL-Press, Bronkhorst, The Netherlands: $\Delta \mathrm{P} \max =100 \pm 0.5 \mathrm{kPa}$ ) and the flux was measured using a balance (Mettler-Toledo P3002). The retentate and permeate lines were drained without recirculating the water. During two-phase flow cleaning, nitrogen gas was introduced in the liquid line before the filtration cells, controlled by a mass flow controller (EL-Flow, Bronkhorst, The Netherlands: $500 \pm 0.25 \mathrm{~mL} / \mathrm{min}$ ). The filtration cells were custom-made and manufactured from PMMA plates with a stainless steel frame to allow for operation at moderate pressures (maximum operating pressure of $600 \mathrm{kPag}$ ).

The filtration test procedures were similar as described in our previous work (Wibisono et al. 2015). Each sample of modified feed spacer was tested in two stages: (1) $a$ fouling stage; biofouling growth in the spacer-filled channel causing at least $300 \%$ FCP increase over the feed channel; and (2) a cleaning stage; two-phase flow cleaning to remove biofouling.

During the fouling stage, fresh NF membranes were used in each experiment and each hydrogel-coated feed spacer was tested in a separate experimental run. Prior to use, the membranes were soaked in Milli-Q water overnight to remove preservation liquid after which the filtration cells were closed. The liquid superficial velocity was set at $0.11 \mathrm{~m} / \mathrm{s}$ by mass flow 
controllers and pump speed, and the TMP was set at $600 \mathrm{kPag}$. To enhance biofouling growth, nutrients (sodium acetate $\left(\mathrm{CH}_{3} \mathrm{COONa}\right)$, sodium nitrate $\left(\mathrm{NaNO}_{3}\right)$, and anhydrous monobasic sodium phosphate $\left.\left(\mathrm{NaH}_{2} \mathrm{PO}_{4}\right)\right)$, were added to the feed water in a molar ratio $\mathrm{C}: \mathrm{N}: \mathrm{P}=$ 100:20:10. The nutrient concentration was set at $1 \mathrm{mg} \mathrm{Ac-C/L}$, aiming at an experimental run of approximately 6-7 days for uncoated feed spacers.

The FCP and flux were recorded at least once per day for each filtration cell, and the biofouling growth in the filtration cells was observed daily in situ using optical coherence tomography (OCT) (Ganymede Spectral Domain OCT, Thorlabs GmbH, Germany). The OCT was set at a field of view (B-scans) of $x=10 \mathrm{~mm}$ and $\mathrm{z}=1.5 \mathrm{~mm}$, with pixel size $5429 \mathrm{x} 546$. As shown in Figure 4, the observation area is located in the middle of the filtration cell (blue square) and the red arrow indicates the scanning direction, which is identical to the flow direction. The refractive index of water (1.33) was used since the light beam passes the wetted biofouling layer in the feed channel. The acquisition time was $2.018 \mathrm{~s}$. All tomograms are presented as obtained, the orange scale intensity is proportional to the intensity of the detected reflection of the raw signal.

When the FCP of a specific filtration cell increased by at least $300 \%$, the fouling stage was considered to be complete and the cleaning stage was started. During the cleaning stage, the liquid velocity was set at $0.44 \mathrm{~m} / \mathrm{s}$, and nitrogen gas was introduced into the liquid using a mass flow controller at a gas/liquid ratio $\theta=0.5$. The TMP was set at $0 \mathrm{kPag}$ during the 10 minutes of two-phase flow cleaning. FCP and flux before and after two-phase flow cleaning were measured, and the cleaning efficiency was calculated based on the recovery of the FCP to the initial pressure drop at day 0 , and the flux recovery to the clean water flux of the membrane (Wibisono et al. 2015).

The two-phase flow cleaning efficiency was represented as FCP-based cleaning efficiency or FCP recovery, which was calculated using: 
$\eta_{(F C P)}=\frac{\Delta P_{300 \% \text { fouled }}-\Delta P_{\text {cleaned }}}{\Delta P_{300 \% \text { fouled }}-\Delta P_{0}} \cdot 100 \%$

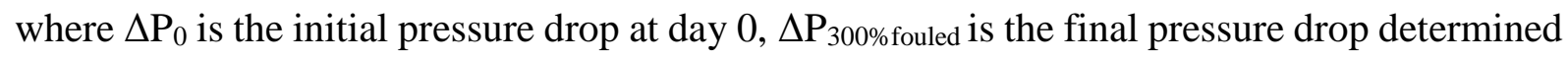
just before two-phase flow cleaning and $\Delta \mathrm{P}_{\text {cleaned }}$ is the pressure drop after two-phase flow cleaning. All $\Delta \mathrm{P}$ values are normalized to the lowest $\Delta \mathrm{P}_{0}$ of all runs.

The flux-based cleaning efficiency is presented as MTC recovery and calculated using: $\quad \eta_{M T C}=\frac{M T C_{\text {fouled }}-M T C_{\text {cleaned }}}{M T C_{\text {fouled }}-M T C_{0}} \cdot 100 \%$

where $\mathrm{MTC}_{0}$ is the initial MTC $=4.9 \times 10^{-11} \mathrm{~m} / \mathrm{s} . P a$ (Wibisono et al. 2015), $\mathrm{MTC}_{\text {fouled }}$ is the final MTC before two-phase flow cleaning, and $\mathrm{MTC}_{\text {cleaned }}$ is the MTC after two-phase flow cleaning. After the filtration test and subsequent two-phase flow cleaning, the feed spacers were removed from the flow cell and dried in an incubator at $100^{\circ} \mathrm{C}$ for $24 \mathrm{~h}$. The ATR-FTIR spectra of both pristine and polymer-coated PP were then recorded.

\section{Results and Discussion}

\subsection{Coating characterization}

The percentage grafting (PG) of polymer on the feed spacer was calculated using Eq. (1). A slight but consistent $\sim 0.32 \%$ increase in spacer weight was observed for all hydrogels (Table 1). The change relative to the original spacer weight is small and will not affect the geometry of the feed spacer and its hydrodynamics in the feed channel.

The FTIR-ATR spectra of pristine PP, oxygen plasma-treated PP and the three hydrogelcoated PPs are shown in Figure 5. 
As shown in Figure 5, the spectrum of pristine PP is dominated by $\mathrm{C}-\mathrm{H}$-stretching modes from $\mathrm{CH}_{2}$ and $\mathrm{CH}_{3}\left(3000-2800 \mathrm{~cm}^{-1}\right), \mathrm{CH}_{2}$ and $\mathrm{CH}_{3}$ deformations (1456 $\mathrm{cm}^{-1}$ and 1374 $\left.\mathrm{cm}^{-1}\right)$, skeletal vibrations $\left(1162,981\right.$ and $\left.971 \mathrm{~cm}^{-1}\right)$, and $\mathrm{CH}_{2}$ rocking $\left(845\right.$ and $\left.806 \mathrm{~cm}^{-1}\right)$. After 15 minutes of exposure to oxygen plasma, ester carbonyl $(\mathrm{C}=\mathrm{O})$ absorptions from aldehyde, keton and acid groups $\left(1730 \mathrm{~cm}^{-1}\right)$ and carbonyl from amides $\left(1643 \mathrm{~cm}^{-1}\right)$ are observed (Lee et al. 1997). Weak O-H stretching bands from hydroxide $\left(3000-3200 \mathrm{~cm}^{-1}\right)$ peroxide $\left(3525 \mathrm{~cm}^{-1}\right)$ are observed as well (Lee et al. 1997). Weak C-O stretching bands from hydroxide and peroxide are visible at 1055 and $1125 \mathrm{~cm}^{-1}$. The presence of polyHEMA-co-PEG ${ }_{10} \mathrm{MA}$, polyDMAEMA and polySPMA is confirmed by their $\mathrm{C}=\mathrm{O}$ ester carbonyl stretching peaks visible at 1712-1726 $\mathrm{cm}^{-1}$ in the FTIR spectra, which is absent in the spectrum of the pristine spacer and slowly increases in the plasma-treated PP spectrum. Sulfonate functional group $(\mathrm{S}=\mathrm{O})$ from SPMA are observed in the polySPMA spectrum at $1041 \mathrm{~cm}^{-1}$. Tertiary amine $\mathrm{C}-\mathrm{H}$ stretching in polyDMAEMA is observed at $2779 \mathrm{~cm}^{-1}$. Furthermore, skeletal $\mathrm{C}-\mathrm{O}-\mathrm{C}$ vibrations of $\mathrm{PEG}$, SPMA and DMAEMA are found at $1100-1160 \mathrm{~cm}^{-1}$. These results indicate that polyHEMAco-PEG ${ }_{10} \mathrm{MA}$, polyDMAEMA and polySPMA are successfully grafted on the PP spacer surface.

The surface roughness and topography of pristine and hydrogel-coated PP spacers were observed by tapping-mode AFM in air (Figure 6).

As shown in Figure 6, all hydrogel-coated PP samples exhibit a relatively smooth and homogenous surface compared to pristine PP. The root mean square (RMS) roughnesses of pristine PP, polyHEMA-co-PEG ${ }_{10} \mathrm{MA}-$ coated PP, polyDMAEMA-coated PP, polySPMAcoated PP are 21.5, 8.1, 10.9 and $15.3 \mathrm{~nm}$, respectively. A more rough topography is observed for both the pristine PP and the oxygen plasma treated PP (not shown), compared to the coated feed spacers. Although there is a variation in RMS values of polyHEMA-co-PEG ${ }_{10} \mathrm{MA}$, polyDMAEMA, and polySPMA coated spacers, differences are minor and obviously all AFM 
measurements reproducibly showed that the hydrogel-coated PP feed spacers had smoother surface than the pristine PP.

\subsection{Coating stability}

The stability of the polymer coatings was evaluated by measuring their weight and IR spectra after incubation in water at $5{ }^{\circ} \mathrm{C}$ for 1 (data not shown), 7 and 30 days at three different $\mathrm{pH}$ values (5, 7 and 9). The weight losses were calculated using Eq. (2) and summarized in Table 2, and the IR spectra are shown in Figure 7.

At shorter incubation times (1 and 7 days), the coating showed good chemical stability as indicated by the only small changes (relative to untreated sample) in polymer weight (Table 2) and the IR spectra (Figure 7). However, at longer incubation times (30 days), a change in weight and IR spectra of the coatings was clearly visible. The weight changes of the coatings were found higher in acidic and basic environment than in neutral environment $(\mathrm{pH} 7)$. This is also visible in the stronger decrease in IR intensities for the coatings exposed for 30 days, compared to those of 7 days exposure. PolyHEMA-co-PEG ${ }_{10}$ MA suffered from significant degradation in acidic and basic environments, which is indicated by the higher weight loss and reduced $\mathrm{C}=\mathrm{O}$ ester carbonyl intensity at $1717 \mathrm{~cm}^{-1}$. In addition, oxidative degradation of the PEG chains (Glastrup 1996) after long exposure to water and acidic and basis environment can occur, as seen as a reduction in the skeletal vibrations of PEG at $1100-1160 \mathrm{~cm}^{-1}$. Although the weight changes of polySPMA and polyDMAEMA in acidic and basic environments were lower than those of polyHEMA-co-PEG ${ }_{10} \mathrm{MA}$, the $\mathrm{C}=\mathrm{O}$ ester carbonyl intensities of polyDMAEMA and polySPMA at 1726 and $1712 \mathrm{~cm}^{-1}$ respectively, the sulfonate peak in poly SPMA at 1041 $\mathrm{cm}^{-1}$ and the tertiary amine of polyDMAEMA at $2779 \mathrm{~cm}^{-1}$ were all found to decrease significantly upon exposure to acidic and basic environments as well. The stronger degradation of polymers immersed in acidic and basic environments for longer times might be caused by 
the increased hydrolytic activity in acidic and basic environments, increasing the loss of hydrophilic polymer chain segments (Li et al. 2008, Loh 2013).

Understanding the chemical stability of polymers in membrane filtration is important as the polymeric materials might be exposed to different $\mathrm{pH}$ conditions during filtration due to water pollution and microbial activity during the filtration process. In relation to the antibiofouling properties of hydrogel-coated PP spacers investigated in the remainder of this paper, the obtained anti biofouling results are still representative, since the bacterial attachment and filtration tests are conducted up to 7 days, in which the polymer coating shows a stable performance and hardly any degradation.

\subsection{Bacterial attachment test}

To quantify the attachment of bacteria on the charged hydrogel coated PP spacers, attachment experiments using E. coli were performed. E. coli is frequently found in water and an emerging cause of water-borne diseases. It is also a very common model bacteria used in lab experiments due to its rapid growth and inexpensive handling and maintenance. Relative attachment of E. coli on both pristine and hydrogel-coated PP spacers after 1, 4 and $24 \mathrm{~h}$ of incubation is presented in Figure 8.

At shorter incubation time $(1 \mathrm{~h})$, relative attachment of $E$. coli was found to be very low on polySPMA-coated PP surfaces, compared to that on pristine PP, but also compared to polyDMAEMA- and polyHEMA-co-PEG 10 MA-coated PP surfaces. The statistical analysis of these bacterial attachment data shows that the attachment on the anionic polySPMA coating differs significantly $(\mathrm{p}<0.05)$ from that on the neutral polyHEMA-co-PEGMA coating and the pristine PP spacer, but is not significantly different from the cationic polyDMAEMA coating $(\mathrm{p}>0.05)$. The bacterial attachment at the surface gradually increased when the incubation time increased. Relative to the uncoated, pristine PP spacer, the PolySPMA and polyHEMA-co- 
$\mathrm{PEG}_{10} \mathrm{MA}$-coated spacers show a reduced bacterial attachment of about $50 \%(\mathrm{p}>0.05)$ after $24 \mathrm{~h}$ of incubation. We hypothesize that this lower attachment can be associated with the higher degree of hydrophilicity of polyHEMA-co-PEG ${ }_{10} \mathrm{MA}$ and polySPMA. The absence of electrostatic attractive interactions between the E. coli cell walls and the hydrogels might also contribute to the lower degree of attachment. In addition, as the net charge of the cell walls of E. coli at physiological $\mathrm{pH}$ is negative ( $\mathrm{Li}$ and McLandsborough 1999), a repulsive electrostatic interaction between E.coli and the anionic polySPMA can also explain the lower degree of attachment of E.coli on the anionic polySPMA. The relatively high bacterial attachment found for the polyDMAEMA-coated PP spacer probably results from attractive electrostatic interactions.

SEM imaging revealed the adhesion of $E$. coli colonies on the surface of all feed spacers investigated after $1 \mathrm{~h}$ of immersion in bacterial solutions at $37^{\circ} \mathrm{C}$ (Figure 9).

As shown in Figure 9 (top), colonies of E. coli attach both to pristine PP and hydrogel-coated PP feed spacers. E. coli cells attached abundantly at the surface of pristine PP feed spacers compared to the hydrogel-coated PP feed spacers. Less bacteria cells were observed on the surface of the polyDMAEMA-coated and the polyHEMA-co-PEG 10 MAcoated PP feed spacers, and only very few bacteria cells adhered to the surface of the polySPMA-coated PP feed spacer. The images support the aforementioned conclusion that especially the anionic polySPMA coating minimizes bacteria (E. coli) attachment.

Another reason that can contribute to the lower degree of attachment of bacteria on the polySPMA-coated spacer, is the more hydrophilic nature of this coating. Contact angles cannot be measure accurately on the feed spaces meshes, but captive bubble contact angles of polySPMA, polyHEMA-co-PEG ${ }_{10} \mathrm{MA}$ and polyDMAEMA prepared via surface mediated atom transfer radical polymerization (SI-ATRP) on intiator-immobilized gold surfaces at $100 \AA$ thicknesses were $148 \pm 1.2,138 \pm 1.8$, and $134 \pm 1.8$ degrees, respectively (as measured inside the 
bubble). This indicates that the polySPMA layer is more hydrophilic than the two other (polyDMAEMA and polyHEMA-co-PEG ${ }_{10} \mathrm{MA}$ ). Hydrophilicity is an important parameter in determining the anti-biofouling properties of surfaces; in general, more hydrophilic surfaces have better anti-biofouling properties, due to stronger surface hydration. In polySPMA this results from strong ion-dipole interactions between sulfonate ions and water. Water molecules are attracted electrostatically and reoriented to form a hydration shell, whose displacement is associated with a high enthalpic penalty. The hydration of sulfonates in aqueous solution has been simulated(Vchirawongkwin et al. 2012), with the result that around 5 water molecules were coordinated to each sulfonate ion. Unlike cationic polyDMAEMA, where the hydration is influenced by the $\mathrm{pH}$ and greatly reduced at neutral and basic pHdue to deprotonation of the ammonium, the hydration shell of anionic polySPMA is relatively stable at neutral $\mathrm{pH}$, since sulfonic acids are strong (with $\mathrm{pKa}<0$ ), and thus their hydration is rather $\mathrm{pH}$ insensitive. The high repulsion towards E.coli by polySPMA is further enhanced by electrostatic repulsive interactions between the identical negative charges of polySPMA and the bacteria cell wall surfaces which also have a net negative charge. It might be expected that the negatively charged sulfonates interact strongly or form complexes with cations, which could potentially reduce antifouling performance, as is the case for carboxylic acids. However, the difference in structure between carboxylic acids and sulfonates is of considerable importance in this respect: the resonance-stabilized sulfonate has the negative charge delocalized over a larger volume than in the carboxylate. This significantly reduces the tendency of sulfonates to form complexes with cations. For example, calcium and magnesium ions form insoluble precipitates with carboxylates, but not with sulfonates.

In this work, the contact angle of pristine PP was not measured due to the small surface area and the non-flat surface. However, it has been reported (Kang et al. 2001) that unmodified PP membranes have a contact angle (sessile drop contact angle measured in air) of 
$108^{\circ}$ which is hydrophobic. This hydrophobic surface might result in increased attachment of E. coli via hydrophobic interactions.

\subsection{Filtration test and two-phase flow cleaning}

\subsubsection{Dynamics of feed channel pressure drop and water flux}

Feed channel pressure drop and MTC dynamics during filtration (fouling stage and two-phase flow cleaning) using pristine PP spacers and the coated PP spacers are shown in Figure 10.

As shown in the left panel of Figure 10, the growth of biofouling in the feed spacer channels is shown as an increase in feed channel pressure drop (FCP). An exponential growth is observed for uncoated PP, polyHEMA-co-PEG ${ }_{10} \mathrm{MA}-$, and polyDMAEMA- coated feed spacers. The FCP increase of the polyDMAEMA-coated feed spacer shows a significant increase between Day 2 and Day 4 especially. As the fouling stage is considered to be completed when the FCP increase is at least $300 \%$, on Day 4, two-phase flow cleaning was carried out for this polyDMAEMA-coated feed spacer. Longer operation times are required to achieve similar FCP increase for pristine PP and polyHEMA-co-PEG (10 $_{10}$ A-coated PP feed spacers. Interestingly, a long-lasting and linear increase in pressure drop was observed for the polySPMA-coated feed spacer. In contrast to the results observed for the other spacers, the FCP increase for the polySPMA-coated feed spacer develops very slowly and only after one week of operation (Day 7), an FCP increase of 300\% is reached (an increase from an initial FCP of 19 mbar to 60 mbar).

On the other hand, as shown in the right panel of Figure 10, the MTC decrease shows a similar behavior for both uncoated and polymer-coated PP spacers. Consequently, twophase flow cleaning is able to remove biofouling from the feed spacer channels. However, the 
MTC recovery due to two-phase flow cleaning is not as high as the FCP recovery (as will be discussed later; see also Figure 12).

\subsubsection{Daily OCT observations}

The biofouling growth during the fouling stage of both uncoated and hydrogelcoated PP spacers is observed daily using optical coherence tomography (OCT). Representative tomograms are shown in Figure 11.

As shown in Figure 11, for pristine PP and polyHEMA-co-PEG ${ }_{10} \mathrm{MA}$-coated PP feed spacers 6 days are necessary to achieve a 300\% FCP increase. The tomograms clearly show the presence of biofouling from day 4 on in these cases, at the region between feed spacer filaments and membrane surface. This region has the lowest flow velocity, and layers of biofilms can develop on top of each other. From day 5 on, biofouling clearly becomes more severe on pristine PP and as well as on polyHEMA-co-PEG ${ }_{10} \mathrm{MA}$-coated PP feed spacers. After two-phase flow cleaning on Day 6, the filaments of the polyHEMA-co-PEG ${ }_{10}$ MA-coated feed spacer look cleaner than those of the pristine PP feed spacer filaments after two-phase flow cleaning on day 7 . This implies that biofouling attached to the polyHEMA-co-PEG ${ }_{10} \mathrm{MA}-$ coated PP feed spacer surface is easier to remove by two-phase flow cleaning than that on the pristine PP feed spacer.

For the polyDMAEMA-coated PP feed spacer, a steep increase in FCP was observed between Day 2 and Day 4. The OCT images support this and a large biofouling matrix is clearly observed, mainly in the regions around the feed spacer filaments. Two-phase flow cleaning removed the majority of the biofouling, but still a lot remained. As the net charge of bacteria commonly causing biofouling is negative (Bereschenko et al. 2010), strong adhesion to the positively charged polyDMAEMA-coated spacers occurs. Oppositely, the strong repulsion between bacteria and the negatively charged polySPMA-coated PP feed spacer 
account for the much better anti fouling properties of this hydrogel coated spacer. During the 7 days fouling stage, significant biofouling development on the surface of polySPMA-coated feed spacer filaments is not observed. The effect of two-phase flow cleaning is obvious, when we compare the OCT tomogram of the cleaned polySPMA channel with the pristine channel at day 0. The hydrophilic polySPMA-coated PP feed spacer is very well suited for easy biofouling removal using two-phase flow.

\subsubsection{Efficiency of two-phase flow cleaning}

The efficiency of the applied two-phase flow cleaning in terms of FCP and MTC recovery is calculated based on both FCP and MTC data using Eq. (3) and Eq. (4) and presented in Figure 12.

In terms of FCP recovery, two-phase flow cleaning is rather effective and powerful to remove a large part of the biofouling from the spacer-filled channel itself, regardless of the presence or absence of a feed spacer coating. The FCP level after two-phase flow cleaning is between $0.5-0.9 \mathrm{kPag}$, although the FCP value before the two-phase flow cleaning was very high (see Figure 10 left panel). When comparing the FCP data of all different spacers, the FCP recovery is equal for all spacer types and recoveries of 60 to $70 \%$ are obtained.

Regarding MTC recovery, pristine PP and polySPMA-coated PP feed spacers yield flux recoveries of about $60 \%$, while polyDMAEMA- and polyHEMA-co-PEG 10 MAcoated PP feed spacers generate lower flux recoveries, below 40\%. Initially, all systems had the same initial flux (as all use the same membrane). However, to reach an FCP increase of 300\%, different operation times are required depending on the type of spacer. For polySPMA-coated PP feed spacers, a 300\% FCP increase was reached after 7 days and during that period, the flux in terms of MTC value decreased to $0.86 \cdot 10^{-11} \mathrm{~m} / \mathrm{s} \cdot \mathrm{Pa}$. After two-phase flow cleaning, the MTC recovered to approximately $3.11 \cdot 10^{-11} \mathrm{~m} / \mathrm{s} \cdot \mathrm{Pa}$, which is close to the initial $\mathrm{MTC}_{0}$ value of $4.9 \cdot 10^{-}$ 
${ }^{11} \mathrm{~m} / \mathrm{s} \cdot \mathrm{Pa}$. The OCT image of the polySPMA-coated PP feed spacer after cleaning supports this and shows an almost identically clean feed channel as on day 0 (see Figure 11). Similar behavior is observed for pristine PP. For polyHEMA-co-PEG ${ }_{10} \mathrm{MA}$-coated PP feed spacers, although the MTC of the fouled system is identical to the MTC value of the fouled polySPMA-coated PP and pristine PP, the MTC recovery after two-phase flow cleaning is lower. This is the same for polyDMAEMA-coated PP spacers, since also in this case the filtration time to reach $300 \%$ FCP increase is relatively short, resulting in relatively high MTC values when two-phase flow cleaning was applied, resulting in low MTC recoveries.

Based on the FCP- and MTC-recovery data, especially the anionic polySPMAcoated PP feed spacers showed delayed biofouling growth and a delayed FCP increase, resulting in a reduced need for two-phase flow cleaning.

\subsection{Post-filtration analysis}

Foulant characteristics on the surfaces of pristine and hydrogel-coated PP spacers were evaluated by determining the change in weight due to biofouling attachment and measuring the IR spectra of the samples after being exposed to filtration experiments up to 7 days and subsequent two-phase flow cleaning. The FTIR-ATR spectra were recorded after the samples were air dried at room temperature. Spectra are shown in Figure 13.

The N-H band of Amide A is normally seen at 3270-3310 $\mathrm{cm}^{-1}$ (Creighton 2002, Khan et al. 2013, Krimm and Bandekar 1986, Krimm and Dwivedi 1982) and its specific IR frequencies depend on the structure of the amino acids present. For example, $\alpha$-Poly-alanine has an N-H stretching bond of the amide A near $3300 \mathrm{~cm}^{-1}$ (Rabolt et al. 1977), for polyglycine II this is $3303 \mathrm{~cm}^{-1}$ (Dwivedi and Krimm 1982) and for Ca-poly(L-glutamate) this can be found at $3275 \mathrm{~cm}^{-1}$ (Sengupta et al. 1984). In this work, prominent signals of the N-H band of Amide A are clearly observed at $3284-3290 \mathrm{~cm}^{-1}$ on the surface of pristine PP, polyDMAEMA-coated 
and polyHEMA-co-PEG 10 MA-coated PP spacers (Fig. 13). Furthermore, on these three samples, amide I and II are also observed at $1641-1653 \mathrm{~cm}^{-1}$ and $1537-1543 \mathrm{~cm}^{-1}$, respectively. These results suggest the presence of proteins on the surface of pristine PP, polyDMAEMA and polyHEMA-co-PEG ${ }_{10}$ MA spacers. The presence of a phosphodiester backbone of nucleic acid is clearly found for pristine PP and polyDMAEMA surfaces, as suggested by the bands at 1236 and $1238 \mathrm{~cm}^{-1}$. In addition, the peak at $1080 \mathrm{~cm}^{-1}$ faintly found on pristine PP suggests the presence of $\mathrm{C}-\mathrm{O}$ and $\mathrm{C}-\mathrm{O}-\mathrm{C}$ from sugars (Khan et al. 2013). These results suggest the presence of biological materials on the surface of pristine PP, polyDMAEMA and polyHEMA-co$\mathrm{PEG}_{10} \mathrm{MA}$. Interestingly, these fingerprints were not found on the surface of the polySPMAcoated PP spacers and supports the previous results obtained from bacterial attachment experiments, FCP and MTC data and OCT images.

The foulants on the surface of pristine and polymer-coated PP spacers were visualized by SEM and the images are shown in Figure 14. Foulants were found to be omnipresent on the surface of pristine PP. Fouling was less dominant on the surface of polyHEMA-co-PEG ${ }_{10}$ Ma-coated and polyDMAEMA-coated spacers and lowest on the anionic polySPMA-coated spacer. These images also demonstrate that the coating of hydrogels on spacer surfaces and especially the application of an anionic polySPMA coating enhance the performance of the membrane process and the effectiveness of two-phase flow cleaning.

\section{Conclusion}

PolyHEMA-co-PEG ${ }_{10}$ MA (0), polyDMAEMA (+) and polySPMA (-) were successfully coated on PP feed spacer surfaces via plasma mediated UV-polymerization. These coatings are chemically stable for at least 7 days upon immersion into neutral, acidic and basic environments. All hydrogel-coated PP samples showed improved anti-biofouling properties during bacterial attachment tests. During filtration experiments, polyDMAEMA shows low 
anti-biofouling properties due to hydrophobic interactions. The performance of polyHEMA-coPEG $_{10}$ MA is fairly good. PolySPMA-coated PP feed spacers on the contrary show significant anti-biofouling properties. Employing this highly hydrophilic surface during removal of biofouling by two-phase flow cleaning also showed enhanced cleaning efficiency, feed channel pressure drop and flux recoveries. A combination of polySPMA-coated PP feed spacers and two-phase flow cleaning therefore is promising and an environmentally friendly approach to control biofouling in NF/RO systems employing spiral-wound membrane modules. However, would be also interesting to compare the antifouling performance of this anionic polySPMA with the well-known nonfouling zwitterionic or mixed-charged coatings in future works.

\section{Acknowledgments}

This work was performed in the cooperation framework of Wetsus, centre of excellence for sustainable water technology (www.wetsus.nl). Wetsus is co-funded by the Dutch Ministry of Economic Affairs and Ministry of Infrastructure and Environment, the European Union Regional Development Fund, the Province of Fryslân, and the Northern Netherlands Provinces. The authors like to thank the participants of the research theme Advanced Clean Water Technology for the fruitful discussions and their financial support. WY and RN were supported by the European Community's Seventh Framework Program FP7/2007-2013 under Grant Agreement number [237997] (SEACOAT).

\section{Note}

Yusuf Wibisono and Wetra Yandi contributed equally to this work. 


$$
\begin{array}{ll}
\text { Nomenclature } & \\
\text { FCP } & =\Delta \mathrm{P}=\text { feed channel pressure drop }[\mathrm{Pa}] \\
\Delta \mathrm{P}_{0} & =\text { initial feed channel pressure drop }[\mathrm{Pa}] \\
\Delta \mathrm{P}_{\text {fouled }} & =\text { feed pressure drop over the fouled channel }[\mathrm{Pa}] \\
\Delta \mathrm{P}_{\text {cleaned }} & =\text { feed channel pressure drop after two-phase flow cleaning [Pa] } \\
\text { MTC } & =\text { mass transfer coefficient }[\mathrm{m} / \mathrm{Pa} . \mathrm{s}] \\
\mathrm{TMP} & =\text { trans-membrane pressure }[\mathrm{Pa}] \\
\mathrm{u}_{\mathrm{L}} & =\text { superficial liquid velocity }[\mathrm{m} / \mathrm{s}] \\
\eta & =\text { two-phase flow cleaning efficiency }[\%] \\
\theta & =\text { gas/liquid ratio [-] }
\end{array}
$$




\section{References}

Applegate, L.E., Erkenbrecher Jr, C.W. and Winters, H. (1989) New chloroamine process to control aftergrowth and biofouling in permasepR B-10 RO surface seawater plants. Desalination 74(0), 51-67.

Araújo, P.A., Kruithof, J.C., Van Loosdrecht, M.C.M. and Vrouwenvelder, J.S. (2012a) The potential of standard and modified feed spacers for biofouling control. Journal of Membrane Science 403-404, 58-70.

Araújo, P.A., Miller, D.J., Correia, P.B., Van Loosdrecht, M.C.M., Kruithof, J.C., Freeman, B.D., Paul, D.R. and Vrouwenvelder, J.S. (2012b) Impact of feed spacer and membrane modification by hydrophilic, bactericidal and biocidal coating on biofouling control. Desalination 295, 1-10.

Baker, J., Stephenson, T., Dard, S. and Côté, P. (1995) Characterisation of Fouling of Nanofiltration Membranes used to Treat Surface Waters. Environmental Technology 16(10), 977-985.

Bereschenko, L., Stams, A., Euverink, G. and van Loosdrecht, M. (2010) Biofilm formation on reverse osmosis membranes is initiated and dominated by Sphingomonas spp. Applied and environmental microbiology 76(8), 2623-2632.

Bereschenko, L.A., Prummel, H., Euverink, G.J.W., Stams, A.J.M. and van Loosdrecht, M.C.M. (2011) Effect of conventional chemical treatment on the microbial population in a biofouling layer of reverse osmosis systems. Water Research 45(2), 405-416.

Chang, Y., Yandi, W., Chen, W.-Y., Shih, Y.-J., Yang, C.-C., Chang, Y., Ling, Q.-D. and Higuchi, A. (2010) Tunable Bioadhesive Copolymer Hydrogels of Thermoresponsive Poly(N-isopropyl acrylamide) Containing Zwitterionic Polysulfobetaine. Biomacromolecules 11(4), 1101-1110.

Creber, S.A., Vrouwenvelder, J.S., van Loosdrecht, M.C.M. and Johns, M.L. (2010) Chemical cleaning of biofouling in reverse osmosis membranes evaluated using magnetic resonance imaging. Journal of Membrane Science 362(1-2), 202-210.

Creighton, T.E. (2002) Proteins : Structures and molecular properties W.H. Freeman and Company, New York.

Dwivedi, A.M. and Krimm, S. (1982) Vibrational Analysis of Peptides, Polypeptides, and Proteins .15. Crystalline Polyglycine-Ii. Biopolymers 21(12), 2377-2397.

Ekblad, T., Bergström, G., Ederth, T., Conlan, S.L., Mutton, R., Clare, A.S., Wang, S., Liu, Y., Zhao, Q., D’Souza, F., Donnelly, G.T., Willemsen, P.R., Pettitt, M.E., Callow, M.E., 
Callow, J.A. and Liedberg, B. (2008) Poly(ethylene glycol)-Containing Hydrogel Surfaces for Antifouling Applications in Marine and Freshwater Environments. Biomacromolecules 9(10), 2775-2783.

Glastrup, J. (1996) Degradation of polyethylene glycol. A study of the reaction mechanism in a model molecule: Tetraethylene glycol. Polymer Degradation and Stability 52(3), 217222.

Greenlee, L.F., Lawler, D.F., Freeman, B.D., Marrot, B. and Moulin, P. (2009) Reverse osmosis desalination: Water sources, technology, and today's challenges. Water Research 43(9), 2317-2348.

Hausman, R., Gullinkala, T. and Escobar, I.C. (2010) Development of copper-charged polypropylene feedspacers for biofouling control. Journal of Membrane Science 358(12), 114-121.

Hijnen, W.A.M., Castillo, C., Brouwer-Hanzens, A.H., Harmsen, D.J.H., Cornelissen, E.R. and van der Kooij, D. (2012) Quantitative assessment of the efficacy of spiral-wound membrane cleaning procedures to remove biofilms. Water Research 46(19), 6369-6381.

Hilal, N., Al-Zoubi, H., Darwish, N.A., Mohammad, A.W. and Abu Arabi, M. (2004) A comprehensive review of nanofiltration membranes: Treatment, pretreatment, modelling, and atomic force microscopy. Desalination 170(3), 281-308.

Kang, M.S., Chun, B. and Kim, S.S. (2001) Surface modification of polypropylene membrane by low-temperature plasma treatment. Journal of Applied Polymer Science 81(6), 15551566.

Khan, M.T., Manes, C.L.D., Aubry, C. and Croue, J.P. (2013) Source water quality shaping different fouling scenarios in a full-scale desalination plant at the Red Sea. Water Research 47(2), 558-568.

Krimm, S. and Bandekar, J. (1986) Vibrational Spectroscopy and Conformation of Peptides, Polypeptides, and Proteins. Advances in Protein Chemistry 38, 181-364.

Krimm, S. and Dwivedi, A.M. (1982) Vibrational Analysis of Peptides, Polypeptides and Proteins .12. Fermi Resonance Analysis of the Unperturbed Nd Stretching Fundamental in Polypeptides. Journal of Raman Spectroscopy 12(2), 133-137.

Lee, S.D., Sarmadi, M., Denes, F. and Shohet, J.L. (1997) Surface modification of polypropylene under argon and oxygen-RF-plasma conditions. Plasmas and Polymers 2(3), 177-198. 
Li, J., Jiang, G. and Ding, F. (2008) The effect of $\mathrm{pH}$ on the polymer degradation and drug release from PLGA-mPEG microparticles. Journal of Applied Polymer Science 109(1), 475-482.

Li, J. and McLandsborough, L.A. (1999) The effects of the surface charge and hydrophobicity of Escherichia coli on its adhesion to beef muscle. International Journal of Food Microbiology 53(2-3), 185-193.

Liu, G.M., Wu, D., Ma, C.C., Zhang, G.Z., Wang, H.F. and Yang, S.H. (2007) Insight into the origin of the thermosensitivity of poly[2-(dimethylamino)ethyl methacrylate]. Chemphyschem 8(15), 2254-2259.

Liu, Y., Ai, K. and Lu, L. (2014) Polydopamine and Its Derivative Materials: Synthesis and Promising Applications in Energy, Environmental, and Biomedical Fields. Chemical Reviews.

Loh, X.J. (2013) The effect of $\mathrm{pH}$ on the hydrolytic degradation of poly( $\varepsilon$-caprolactone)-blockpoly(ethylene glycol) copolymers. Journal of Applied Polymer Science 127(3), 20462056.

Matin, A., Khan, Z., Zaidi, S.M.J. and Boyce, M.C. (2011) Biofouling in reverse osmosis membranes for seawater desalination: Phenomena and prevention. Desalination 281(0), $1-16$.

Miller, D.J., Araújo, P.A., Correia, P.B., Ramsey, M.M., Kruithof, J.C., van Loosdrecht, M.C.M., Freeman, B.D., Paul, D.R., Whiteley, M. and Vrouwenvelder, J.S. (2012) Short-term adhesion and long-term biofouling testing of polydopamine and poly(ethylene glycol) surface modifications of membranes and feed spacers for biofouling control. Water Research 46(12), 3737-3753.

Murosaki, T., Ahmed, N. and Gong, J.P. (2011) Antifouling properties of hydrogels. Science and Technology of Advanced Materials 12(6).

Rabolt, J.F., Moore, W.H. and Krimm, S. (1977) Vibrational Analysis of Peptides, Polypeptides, and Proteins .3. Alpha-Poly(L-Alanine). Macromolecules 10(5), 10651074.

Reid, K., Dixon, M., Pelekani, C., Jarvis, K., Willis, M. and Yu, Y. (2014) Biofouling control by hydrophilic surface modification of polypropylene feed spacers by plasma polymerisation. Desalination 335(1), 108-118.

Sengupta, P.K., Krimm, S. and Hsu, S.L. (1984) Vibrational Analysis of Peptides, Polypeptides, and Proteins .21. Beta-Calcium-Poly(L-Glutamate). Biopolymers 23(8), 1565-1594. 
Stanley, M.S., Callow, M.E. and Callow, J.A. (1999) Monoclonal antibodies to adhesive cell coat glycoproteins secreted by zoospores of the green alga Enteromorpha. Planta 210(1), $61-71$.

Vchirawongkwin, V., Pornpiganon, C., Kritayakornupong, C., Tongraar, A. and Rode, B.M. (2012) The Stability of Bisulfite and Sulfonate Ions in Aqueous Solution Characterized by Hydration Structure and Dynamics. Journal of Physical Chemistry B 116(37), 1149811507.

Vrouwenvelder, J.S., Graf von der Schulenburg, D.A., Kruithof, J.C., Johns, M.L. and van Loosdrecht, M.C.M. (2009) Biofouling of spiral-wound nanofiltration and reverse osmosis membranes: A feed spacer problem. Water Research 43(3), 583-594.

Wan, F., Pei, X., Yu, B., Ye, Q., Zhou, F. and Xue, Q. (2012) Grafting Polymer Brushes on Biomimetic Structural Surfaces for Anti-Algae Fouling and Foul Release. ACS Applied Materials \& Interfaces 4(9), 4557-4565.

Wibisono, Y., Cornelissen, E.R., Kemperman, A.J.B., van der Meer, W.G.J. and Nijmeijer, K. (2014) Two-phase flow in membrane processes: A technology with a future. Journal of Membrane Science 453(0), 566-602.

Wibisono, Y., El Obied, K.E., Cornelissen, E.R., Kemperman, A.J.B. and Nijmeijer, K. (2015) Biofouling removal in spiral-wound nanofiltration elements using two-phase flow cleaning. Journal of Membrane Science 475(0), 131-146. 
Table 1. Percentage grafting of polymer-coated PP feed spacer.

\begin{tabular}{|l|c|}
\hline Polymer type & PG (\%) \\
\hline HEMA-co-PEG ${ }_{10} \mathrm{MA}$ & $0.3203 \pm 0.051$ \\
\hline DMAEMA & $0.3203 \pm 0.064$ \\
\hline SPMA & $0.3205 \pm 0.054$ \\
\hline
\end{tabular}


Table 2. The stability of the hydrogel polymer coating on the PP spacers evaluated by measuring the weight loss of the polymer coating only on the PP spacer after 7 and 30 days incubation in buffer solution at $\mathrm{pH} \mathrm{5,7}$ and 9. The errors represent the standard deviations from three replicates of each sample.

\begin{tabular}{|c|c|c|c|c|c|c|}
\hline \multirow{2}{*}{ Coating } & \multicolumn{6}{|c|}{ Weight loss (mg) } \\
\cline { 2 - 7 } & \multicolumn{3}{|c|}{7 days incubation } & \multicolumn{3}{c|}{30 days incubation } \\
\cline { 2 - 7 } & $\mathrm{pH} 5$ & $\mathrm{pH} \mathrm{7}$ & $\mathrm{pH} \mathrm{9}$ & $\mathrm{pH} 5$ & $\mathrm{pH} \mathrm{7}$ & $\mathrm{pH} 9$ \\
\hline polyHEMA-co-PEG $10 \mathrm{MA}$ & $0.13 \pm 0.07$ & $0.10 \pm 0.00$ & $0.10 \pm 0.00$ & $0.30 \pm 0.10$ & $0.20 \pm 0.00$ & $0.30 \pm 0.10$ \\
\hline polyDMAEMA & $0.10 \pm 0.00$ & $0.10 \pm 0.00$ & $0.17 \pm 0.07$ & $0.23 \pm 0.11$ & $0.20 \pm 0.00$ & $0.17 \pm 0.07$ \\
\hline polySPMA & $0.10 \pm 0.00$ & $0.10 \pm 0.00$ & $0.13 \pm 0.07$ & $0.17 \pm 0.07$ & $0.17 \pm 0.06$ & $0.17 \pm 0.06$ \\
\hline
\end{tabular}




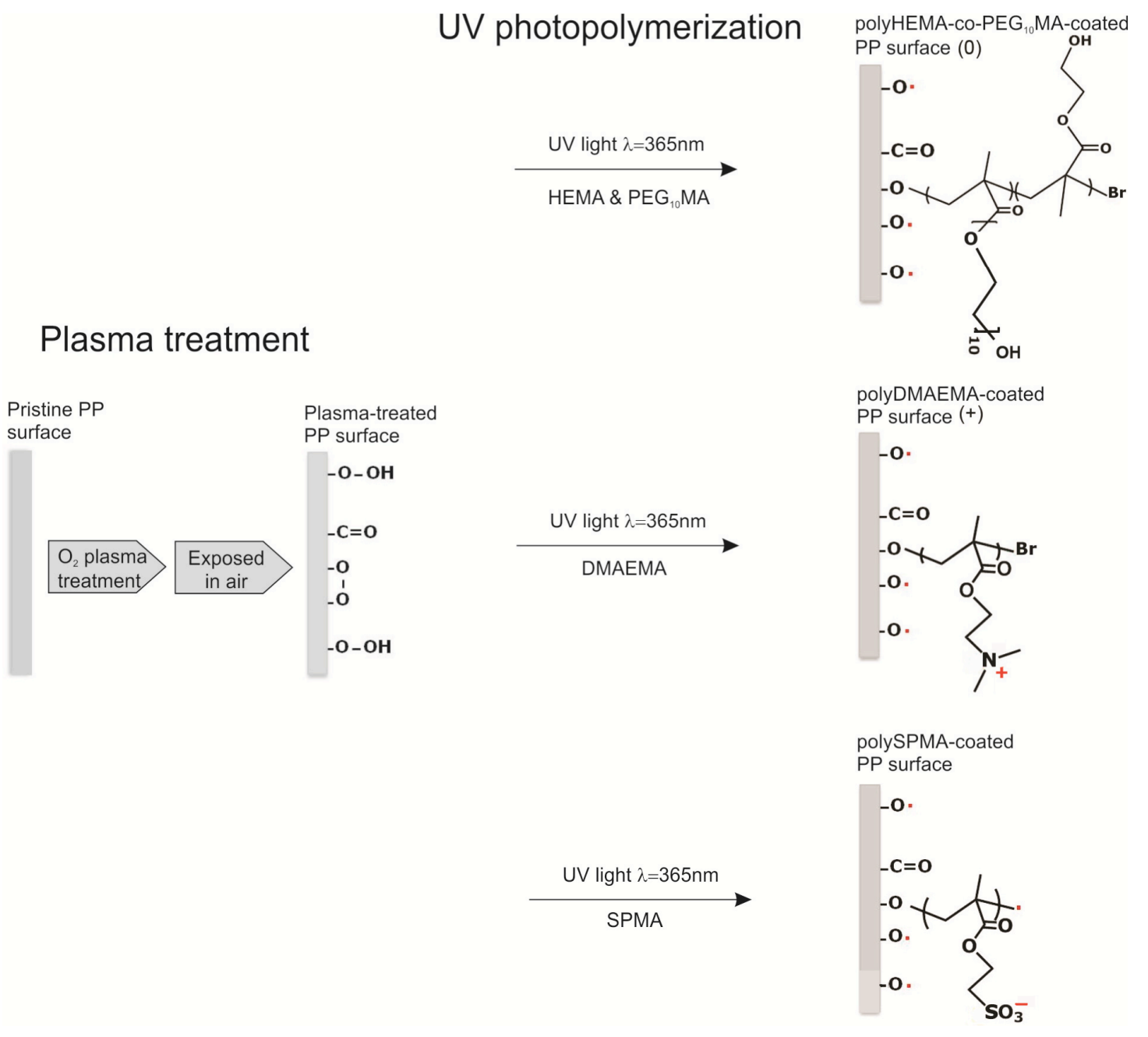

Fig. 1. Reaction scheme of UV-induced grafted polymerization (UV light, $\lambda=365 \mathrm{~nm}$ ) of hydrophilic polymers (polyHEMA-co-PEG10MA, polyDMAEMA or polySPMA) onto a polypropylene (PP) feed spacer surface. PP is treated in oxygen plasma, followed by UV irradiation to attached the monomers (i.e. HEMA/PEG10MA mixture, DMAEMA, or SPMA). The resulting hydrogel polymers grafted to the PP surface have different charges: polyHEMA-co-PEG10MA is neutral $(0)$, polyDMAEMA has a positive charge $(+)$ and polySPMA has a negative charge (-) 
(a) Sonication

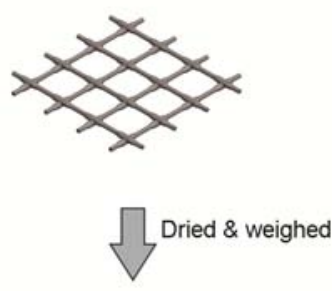

(b) Oxygen plasma treatment
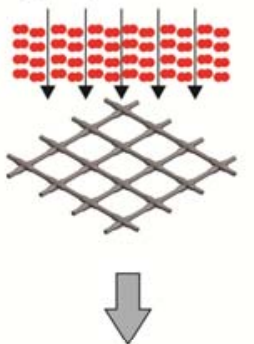

(c) Monomer incubation

HEMA \& PEG ${ }_{10} M A$ (neutral)

SPMA (anionic)

DMAEMA (cationic)

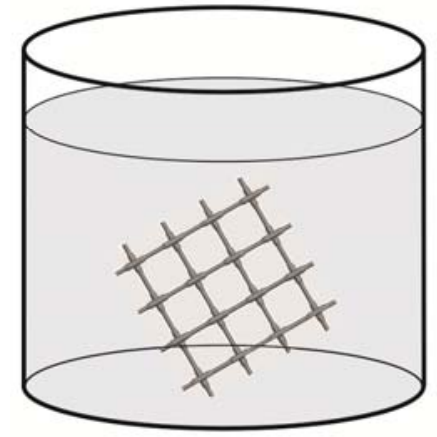

(f) Hydrogel-coated feed spacer

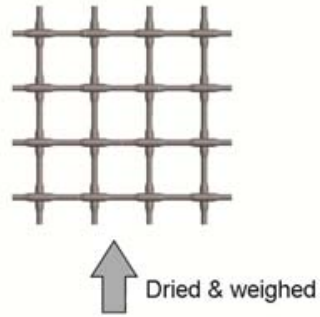

(e) Immersion in water

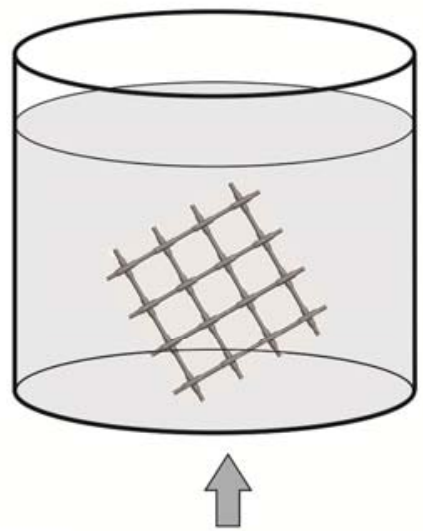

(d) UV-photopolymerization

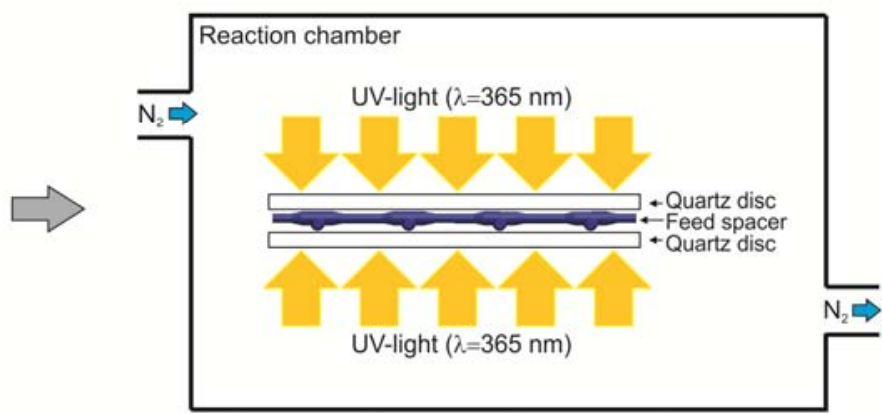

Fig. 2. Plasma mediated UV-polymerization of hydrophilic polymers on polypropylene feed spacers: (a) sonication, $15 \mathrm{~min}$ in acetone; (b) oxygen plasma treatment for $15 \mathrm{~min}$; (c) incubation in monomer solution (HEMA and PEG $_{10}$ MA, DMAEMA, or SPMA) for 24 hours; (d) UV-polymerization $(\lambda=365 \mathrm{~nm})$ for 2 hours; (e) soaking in water for 24 hours; (f) hydrophilized feed spacer after drying. 


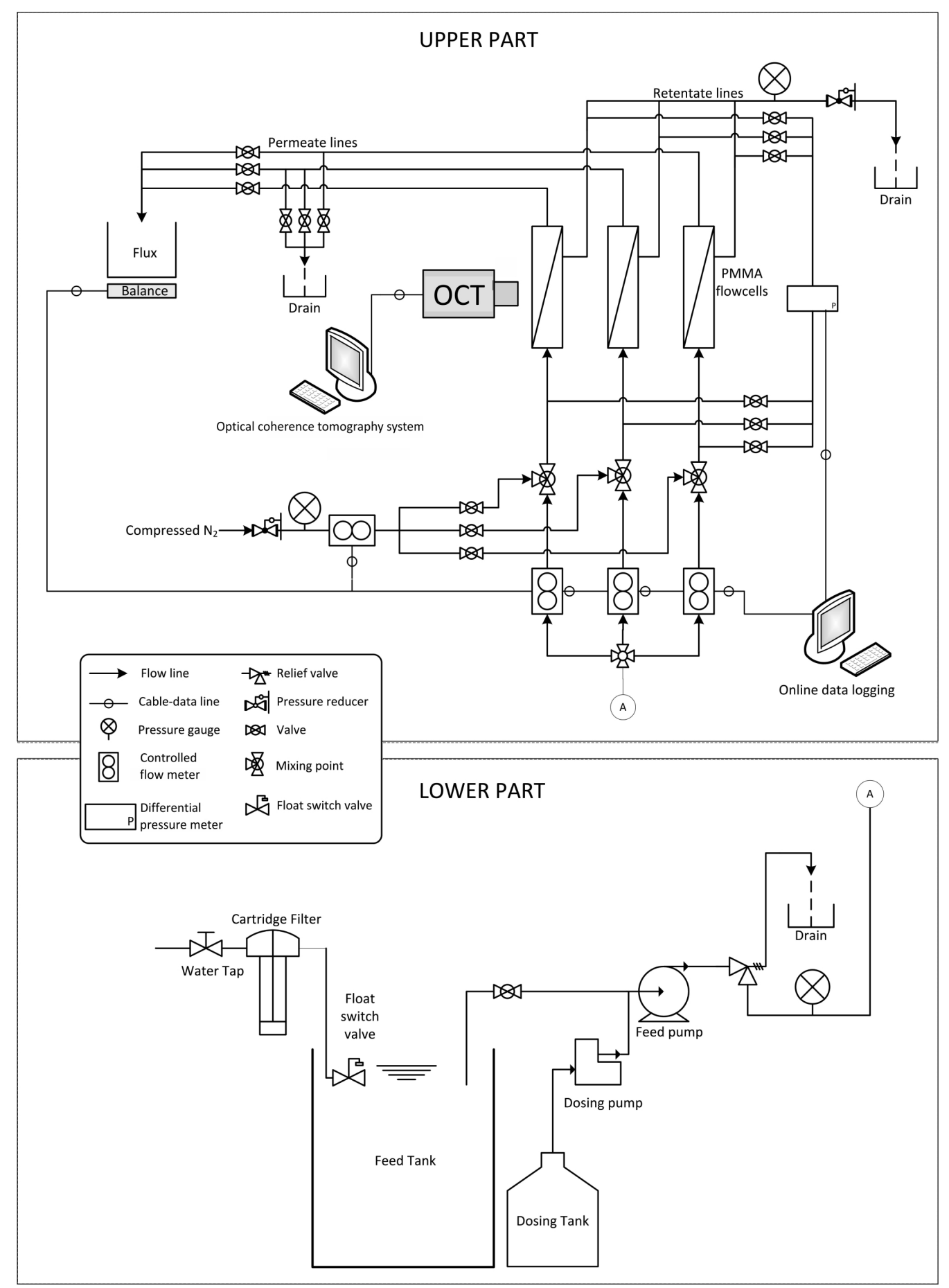

Fig. 3. Experimental set-up used for filtration experiments. The lower part consists of a water tap, cartridge filter, feed tank, dosing tank, dosing pump and feed pump. The upper part consists of mass flow controllers, filtration cells, differential pressure meters, balance and nitrogen gas line; all measurements were controlled and logged using a personal computer. The biofouling growth was observed daily by optical coherence tomography (OCT). 


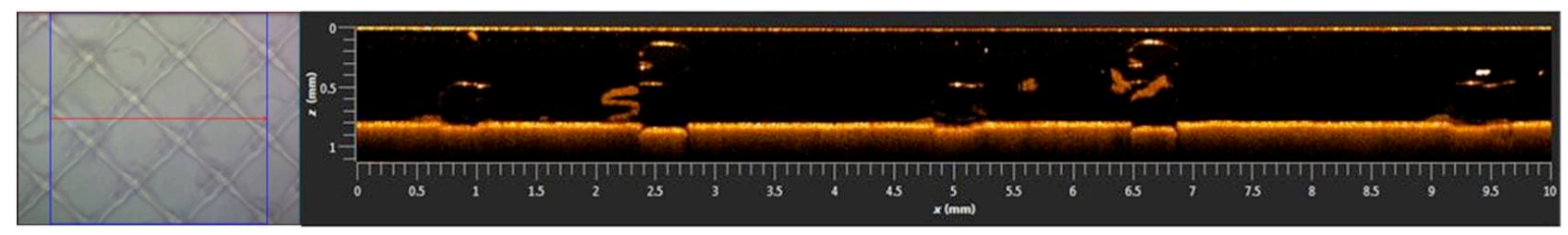

Fig. 4. Left: OCT observation of biofouling in the spacer-filled channels in the middle of the filtration cell; the blue square indicates the observation area and the red arrow is the scan direction, which is in the same direction as the flow direction. Right: OCT image showing a 2D cross-sectional view of the biofouling structure in a spacer-filled filtration channel, exactly at the red line shown in the left picture. Refractive index is 1.33 and the intensity of the detected reflection of the raw signal is presented as the orange scale intensity. Field of view (FOV): $\mathrm{x}=10 \mathrm{~mm}$ and $\mathrm{z}=1.5 \mathrm{~mm}$, with pixel size 5429x546 and acquisition time $2.018 \mathrm{~s}$. 


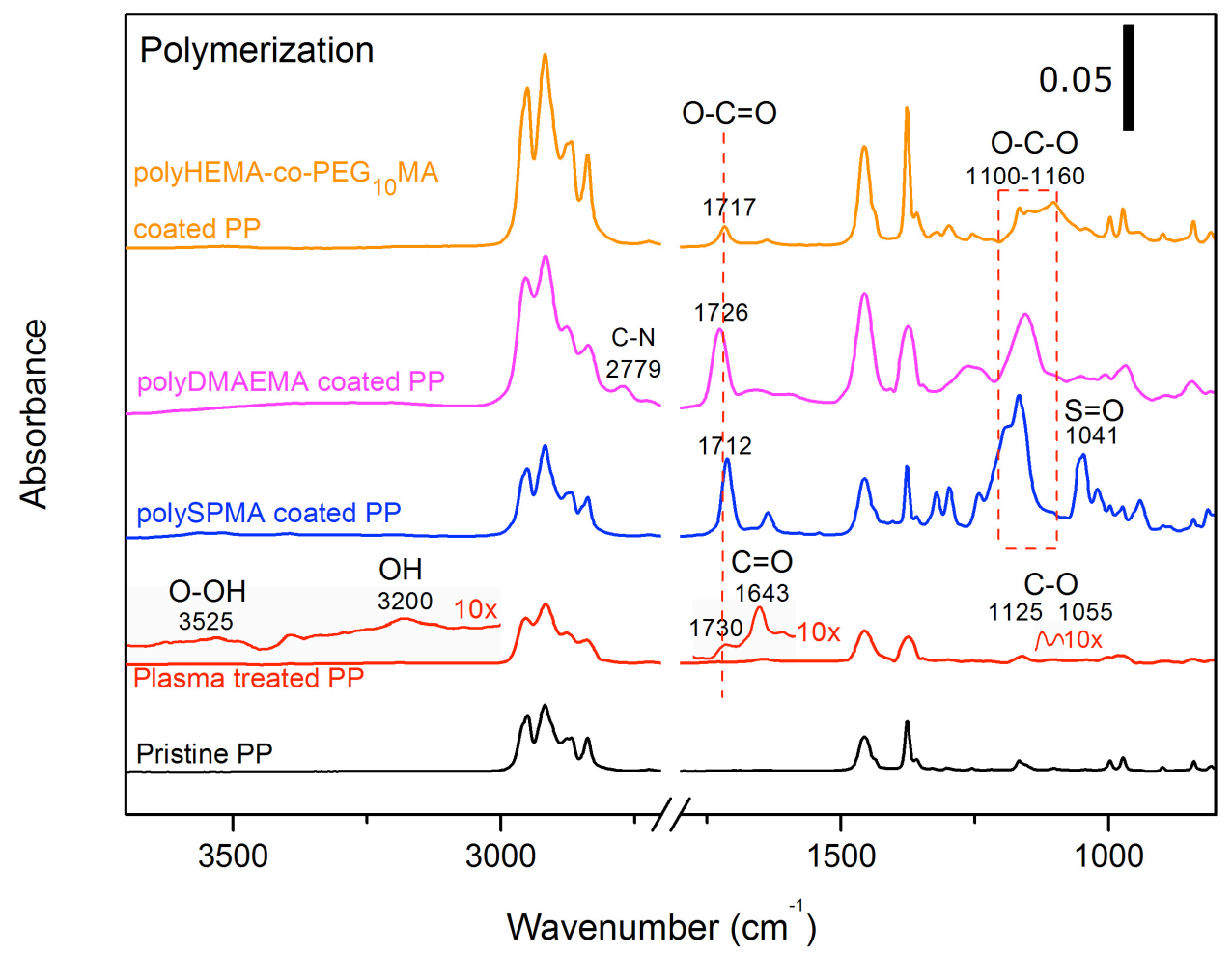

Fig. 5. FTIR-ATR spectra of pristine PP, oxygen plasma-treated $P P$ and hydrogel-coated PP (polyHEMA-co-PEG ${ }_{10} \mathrm{MA}$, polyDMAEMA and polySPMA). The floating bar in right upper corner is the absorbance scale unit. 

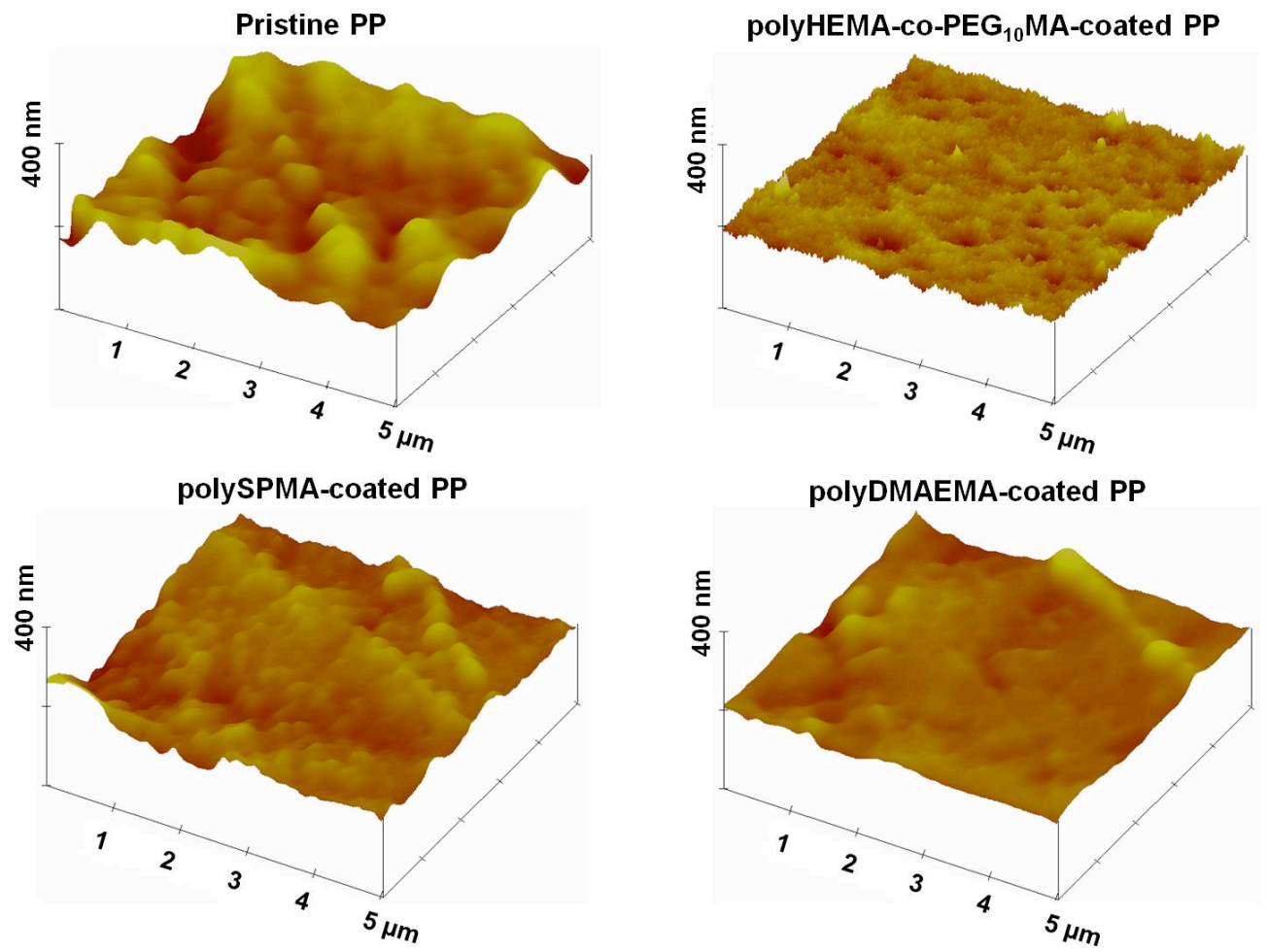

Fig. 6. Surface topography of pristine PP and charged-hydrogel (polyHEMA-co-PEG 10 MA, polyDMAEMA and polySPMA) coated PP feed spacers, measured by tapping mode AFM in air over $5 \times 5 \mu \mathrm{m}^{2}$ areas at an acquisition rate of $1 \mathrm{~Hz}$. 

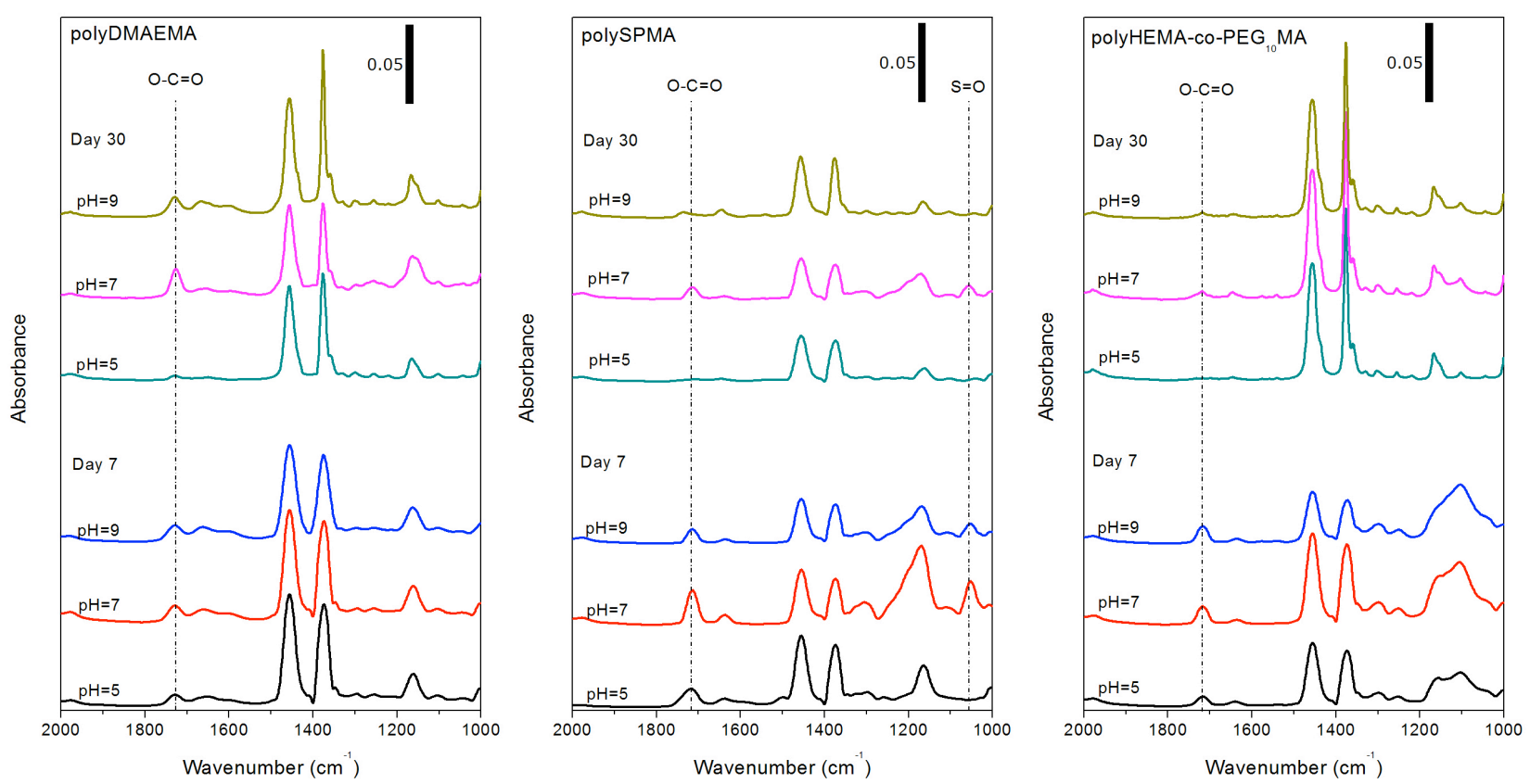

Fig. 7. FTIR-ATR spectra of hydrogel-coated (polyHEMA-co-PEG ${ }_{10} \mathrm{MA}$, polyDMAEMA and polySPMA) PP spacers after incubation in water for 7 and 30 days at three different $\mathrm{pH}$ values (5, 7 and 9). Floating bars in the right upper corner of each spectrum is the absorbance scale unit. 


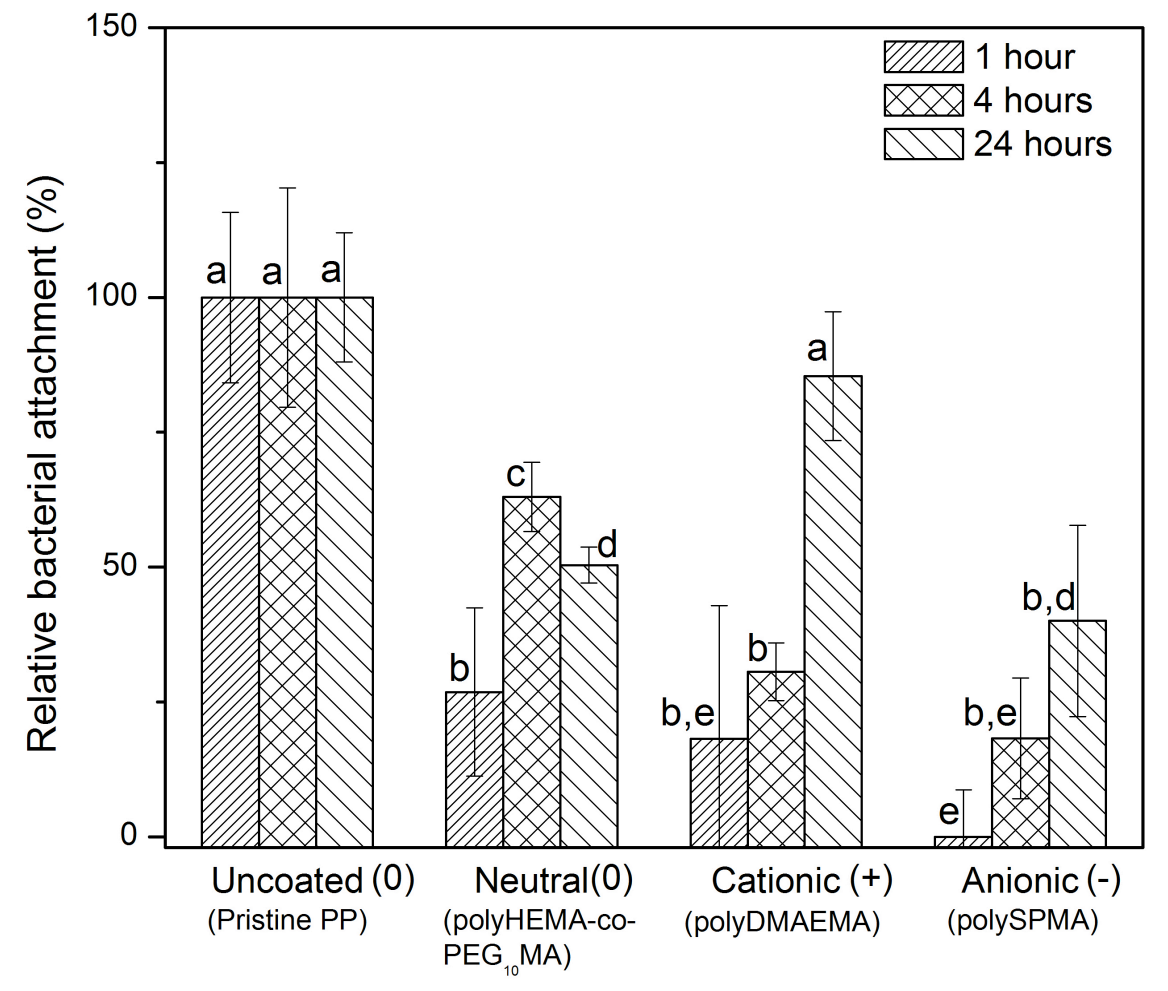

Fig. 8. Relative attachment of $E$. coli cells on pristine and polymer coated PP feed spacer surfaces after 1,4 , and $24 \mathrm{~h}$ of immersion in bacterial solutions at $37^{\circ} \mathrm{C}$. Error bars indicate the standard deviation obtained from four replicates. The different letters above the bars indicate whether the data are significantly different to each other at $p<0.05$. 


\section{Pristine PP}

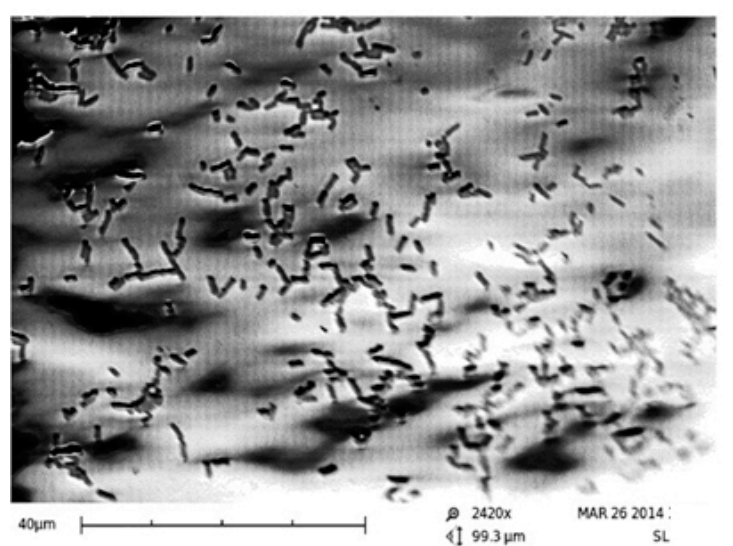

polyDMAEMA

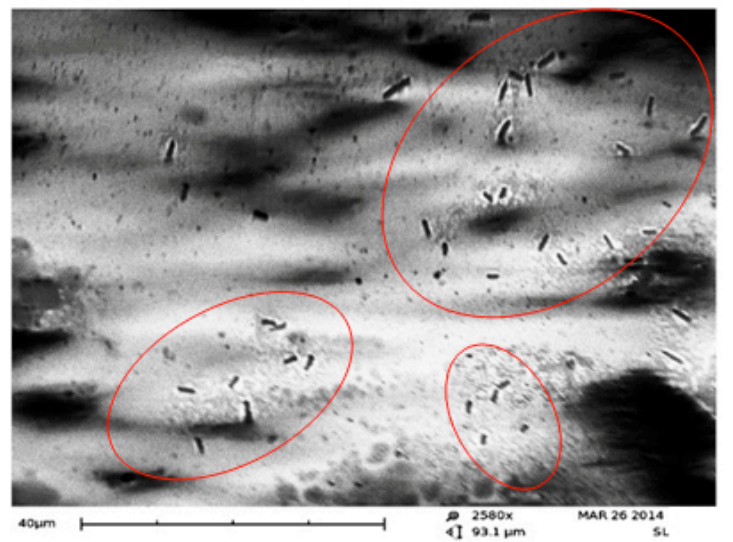

polyHEMA-Co-PEG ${ }_{10} \mathrm{MA}$

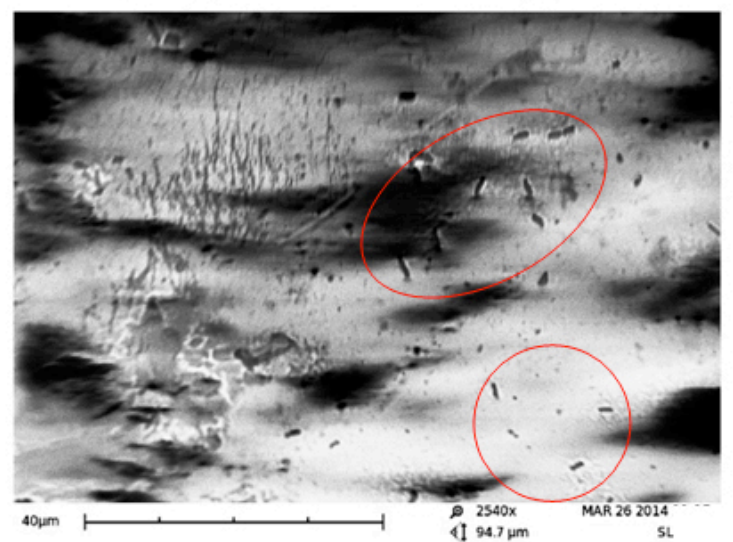

polySPMA

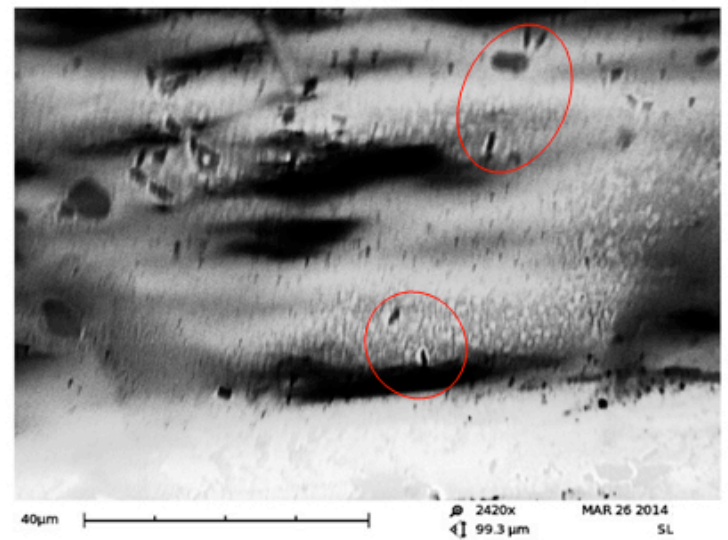

Fig. 9. E. coli cells attached on pristine and coated PP feed spacer surfaces after $1 \mathrm{~h}$ of immersion in bacterial solutions at $37^{\circ} \mathrm{C}$ as observed by SEM (scale bar length is $40 \mu \mathrm{m}$ ). Colonies of bacteria cells adhered on polyDMAEMA-, polyHEMA-co-PEG ${ }_{10} \mathrm{MA}-$ and polySPMA-coated PP feed spacers are shown highlighted in the red circles. 

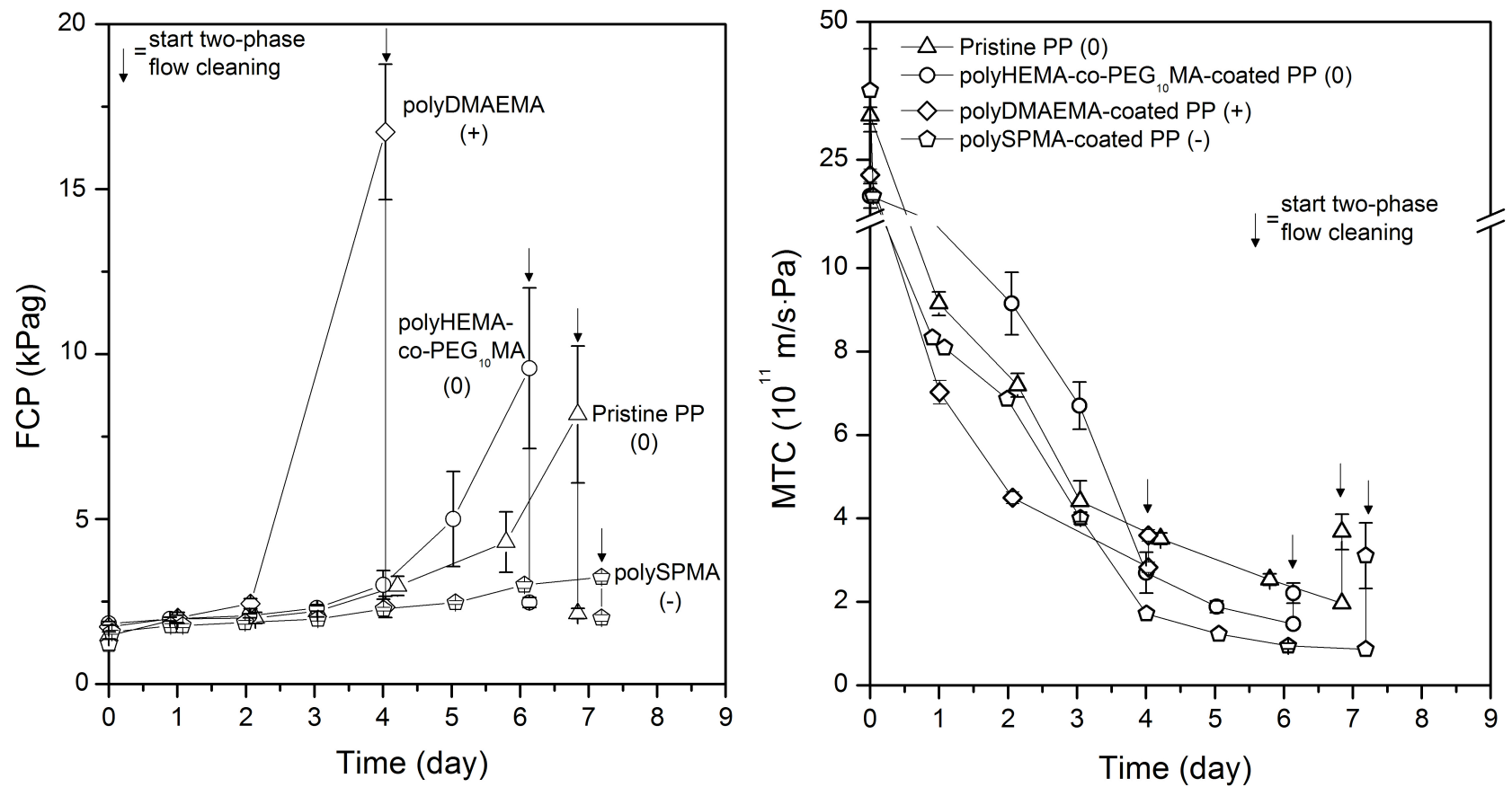

Fig. 10. Left: Feed channel pressure drop (FCP) during biofouling in filtration cells with different feed spacer coatings (pristine PP, polyHEMA-co-PEG ${ }_{10} \mathrm{MA}(0)$, polyDMAEMA $(+)$ and polySPMA (-)), and cleaning by two-phase flow (indicated by arrow). Right: MTC dynamics (pristine PP, polyHEMA-co-PEG $10 \mathrm{MA}$, polyDMAEMA and polySPMA spacers) during fouling stage and two-phase flow cleaning (indicated by arrow). 


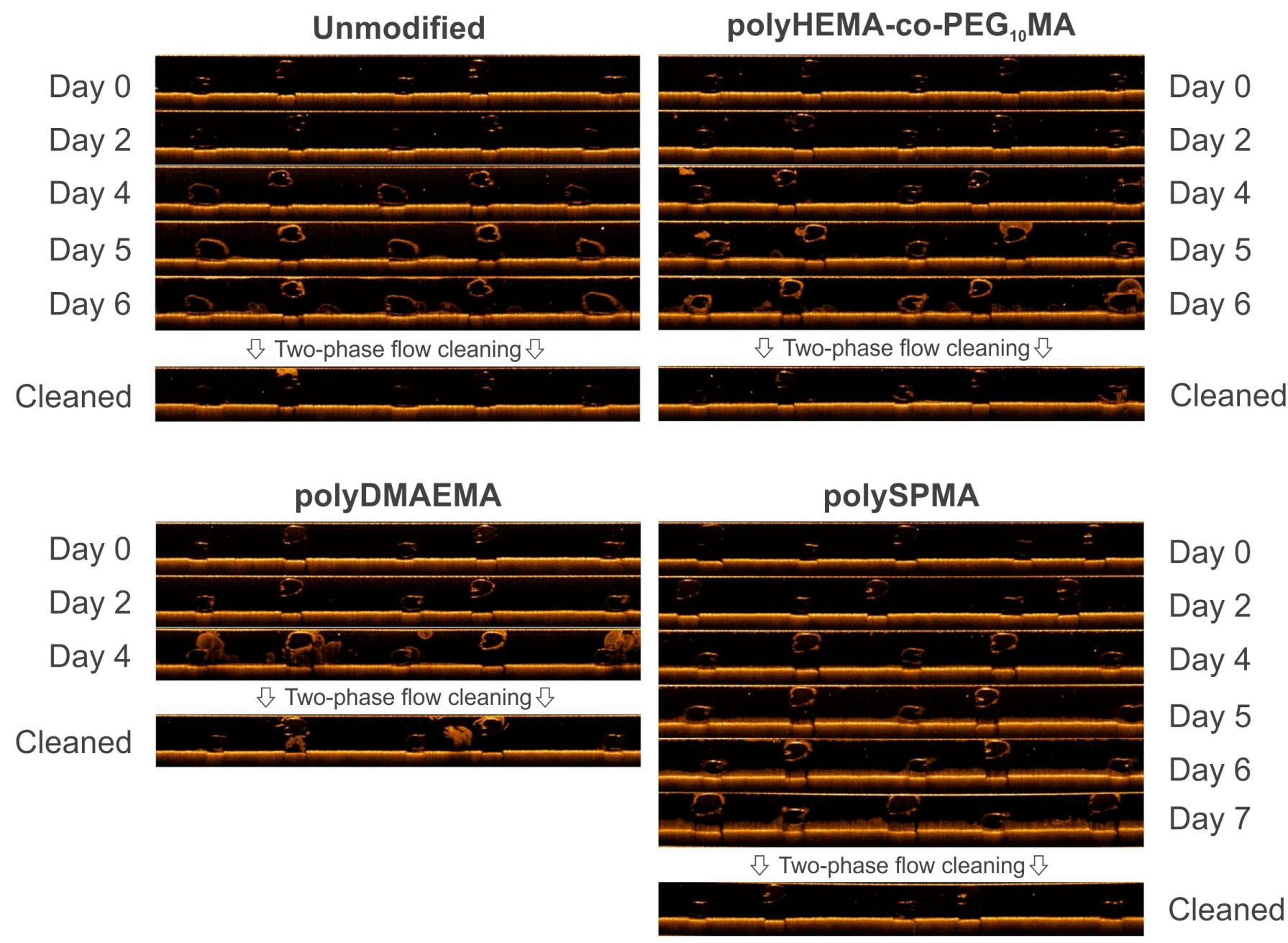

Fig. 11. Series of equidistant OCT images $(1.5 \mathrm{~mm}$ x $10 \mathrm{~mm}$, resolution 5429x546 pixels, measured daily using the refractive index of water (1.33)) of: pristine, polyHEMA-coPEG $_{10}$ MA-coated, polyDMAEMA-coated, and polySPMA-coated polypropylene feed spacerfilled channels during biofouling and after two-phase flow cleaning. Two-phase flow cleaning was conducted at a liquid velocity of $u_{L}=0.44 \mathrm{~m} / \mathrm{s}$ and a gas/liquid ratio of $\theta=0.5$. The orange scale intensity is proportional to the intensity of the detected reflection of the raw signal. Pristine PP spacer: two-phase flow cleaning on day 6; polyDMAEMA-coated spacer: twophase flow cleaning on day 4; polyHEMA-co-PEG 10 MA-coated spacer: two-phase flow cleaning on day 6; polySPMA-coated spacer: two-phase flow cleaning on day 7. 


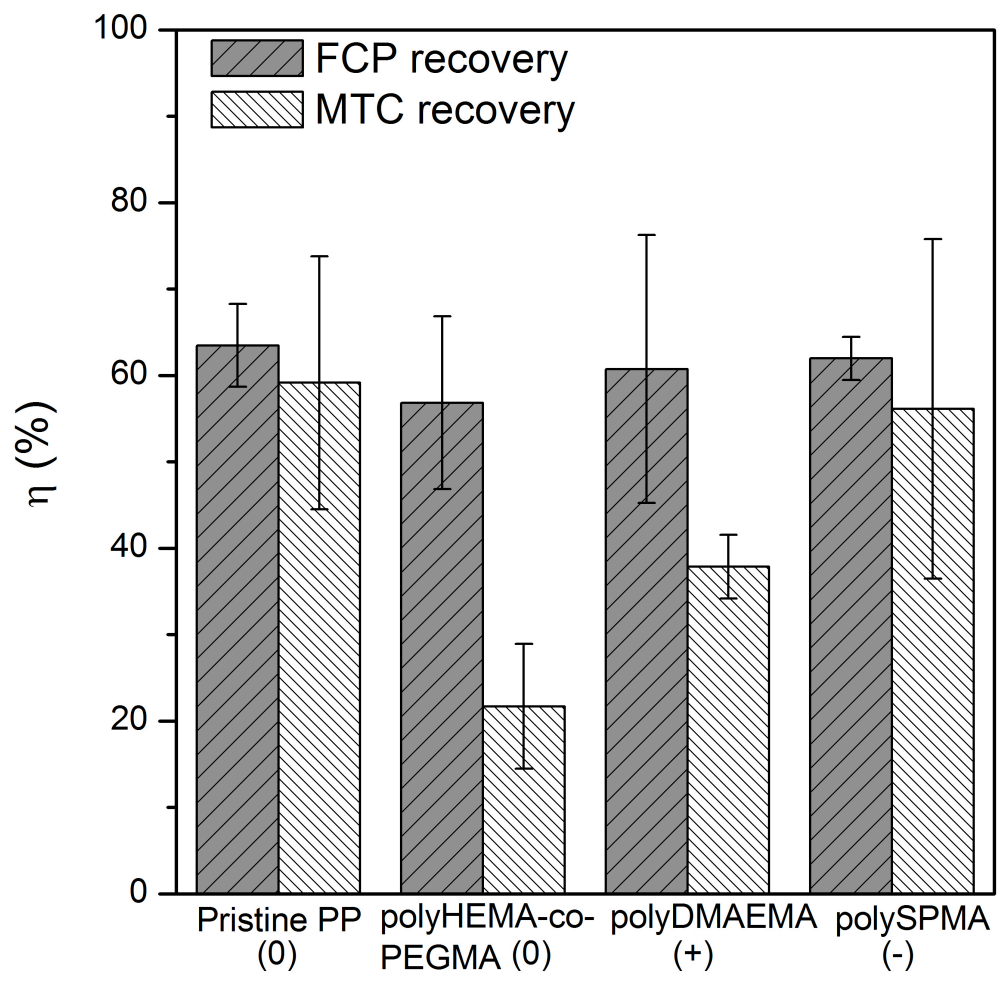

Fig. 12. FCP and MTC recovery by two-phase flow cleaning (pristine PP (0) spacers, polyHEMA-co-PEG ${ }_{10}$ MA $(0)$ coated, polyDMAEMA $(+)$ coated and polySPMA (-) coated PP feed spacers). 


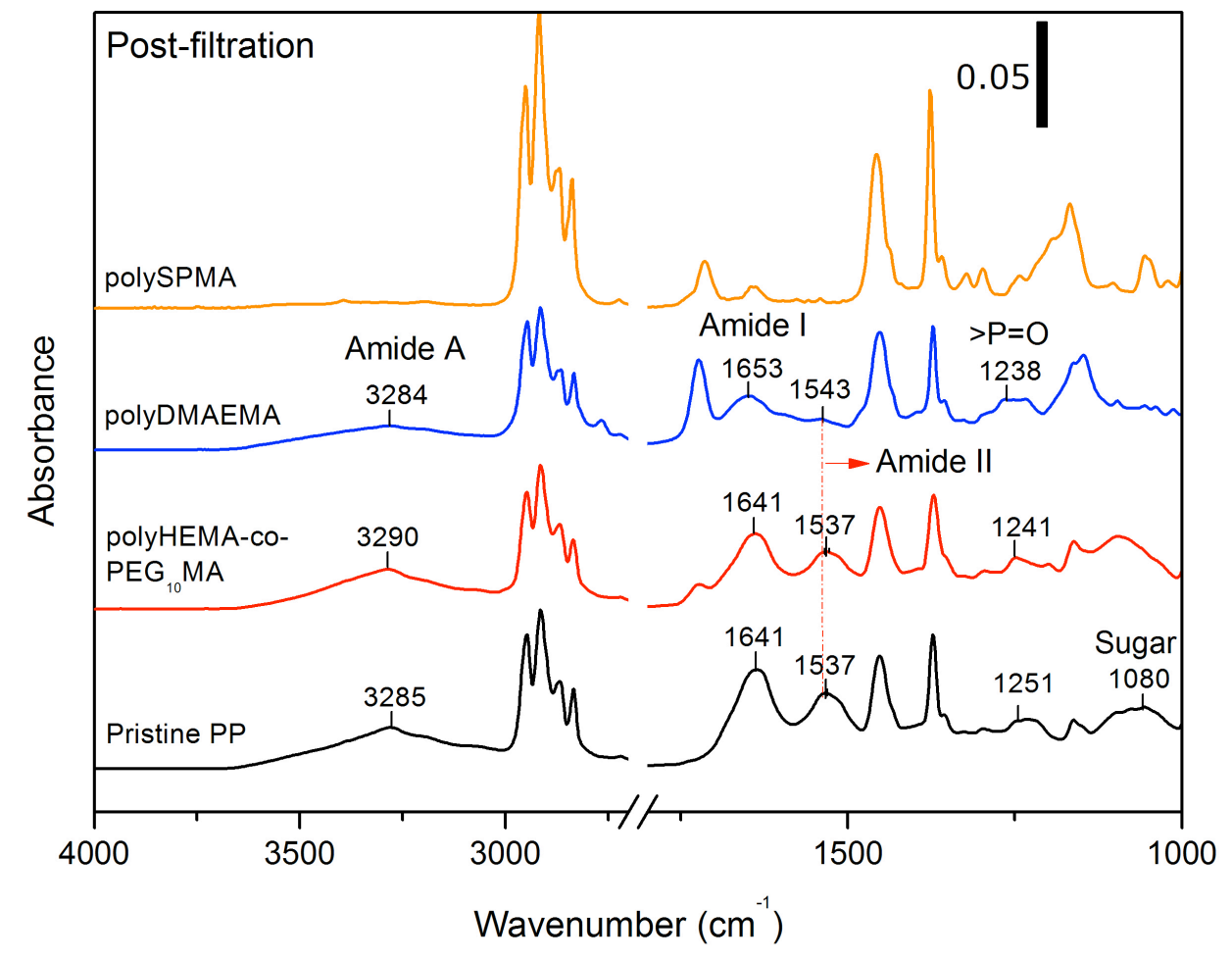

Fig. 13. FTIR-ATR spectra of of pristine PP and the three hydrogel-coated PP spacers after filtration experiments and two-phase flow cleaning. Floating bar in the right upper corner represents the absorbance scale unit. 


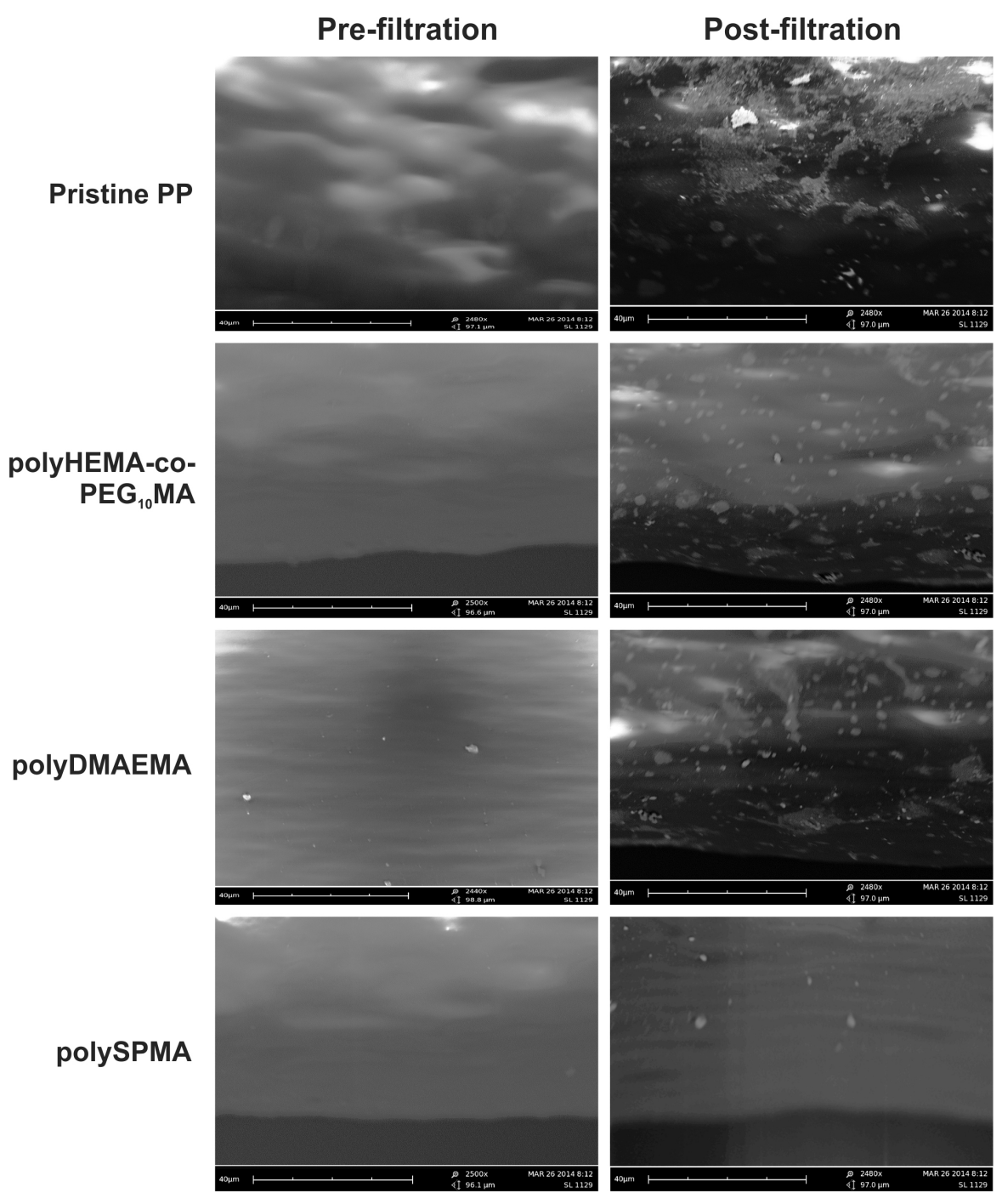

Fig. 14. SEM images of the surface of pristine and polymer-coated PP feed spacers before (left) and after (right) filtration/two-phase flow cleaning (scale bar length is $40 \mu \mathrm{m}$ ). Abundant amounts of biomass are observed on the pristine PP surface, while less biomass is found on the polymer-coated PP feed spacers, and especially the polySPMA-coated spacer. 